\title{
Different p53 Genotypes Regulate PPARy Post- Translational Modification in The Adipogenic Differentiation of Cancer Cells
}

\section{Kexin Zhang}

Tianjin People's Hospital Tianjin Union Medical Center

\section{Qi Zhao}

Tianjin People's Hospital Tianjin Union Medical Center

Zugui Li

Tianjin People's Hospital Tianjin Union Medical Center

Hao Zhang

Tianjin People's Hospital Tianjin Union Medical Center

\section{Fangmei Fu}

Tianjin People's Hospital Tianjin Union Medical Center

Junjie Fu

Tianjin People's Hospital Tianjin Union Medical Center

\section{Minying Zheng}

Tianjin People's Hospital Tianjin Union Medical Center

Shiwu Zhang ( $\square$ zhangshiwu666@aliyun.con )

Tianjin People's Hospital Tianjin Union Medical Center https://orcid.org/0000-0002-5052-2283

\section{Research}

Keywords: PGCCs, adipogenic differentiation, PPARy, p53 genotype

Posted Date: May 19th, 2021

DOI: https://doi.org/10.21203/rs.3.rs-497208/v1

License: (c) (1) This work is licensed under a Creative Commons Attribution 4.0 International License. Read Full License 


\section{Abstract}

Background: Our previous studies confirmed that high concentrations of cobalt chloride $\left(\mathrm{CoCl}_{2}\right)$ can induce the formation of polyploid giant cancer cells (PGCCs). PGCCs have the properties of cancer stem cell. In this study, we demonstrate that PGCCs can be induced to differentiate into adipose in vitro and in vivo. In addition, the molecular mechanism of adipogenic differentiation of PGCCs with daughter cells was investigated by detecting the expression of adipocyte differentiation related proteins in mutant and wild-type $p 53$ cancer cell lines.

Methods: HEY and MDA-MB-231 control cells and PGCCs with daughter cells were cultured with adipogenic differentiation medium and the cell cycle was detected by flow cytometry. The expression of adipocyte differentiation related proteins, and P300 histone acetyltransferase activity were compared before and after adipogenic differentiation. Immunoprecipitation was used to analyze the posttranslational modification of peroxisome proliferator-activator receptor-y (PPARY) and P53 in HEY and MDA-MB-231 control cells and PGCCs with daughter cells cultured with adipogenic differentiation medium. Animal xenograft models were used to study the adipogenic differentiation of PGCCs with daughter cells.

Results: Dexamethasone, rosiglitazone, insulin, and 3-isobutyl-1-methylxanthine (IBMX) can force the trans-differentiation of PGCCs into post-mitotic and functional adipocytes. Activation of PPARY is a critical step in the process of adipogenic differentiation. The expression levels of $p$-CREBser133, PPARy, $\mathrm{C} / \mathrm{EBPa}, \mathrm{C} / \mathrm{EBP} \beta$ were higher in PGCCs with daughter cells after adipogenic differentiation compared with those without adipogenic differentiation in HEY and MDA-MB-231. P53 regulates the acetylation and phosphorylation of PPARY and the expression of P300-Acetyl-PPARY(Lys)-FABP4 and ERK- PhosphoPPARY (Ser112)-FABP4 depended upon the genotype of $p 53$ in HEY and MDA-MB-231 cells after cultured with adipogenic differentiation medium. The invasion and migration abilities of PGCCs with their daughter cells after adipogenic differentiation decreased compared with those cells without adipogenic differentiation.

Conclusion: P300-P53-ERK-CREB-PPARY-CEBPa/ $\beta$-FABP4 pathway may participate in the adipogenic differentiation of HEY, MDA-MB-231 PGCCs with daughter cells, which associated with genotype of $p 53$.

\section{Introduction}

Adipogenic differentiation of human mesenchymal stem cells (MSCs) can be induced by 3-isobutyl-1methylxanthine (IBMX), dexamethasone, and insulin (this being the typical cocktail) [1]. Adipocytes can be derived not only from preadipocytes and pluripotent MSCs but also from cancer stem cells (CSCs). One of the treatments for malignant tumors is induced differentiation therapy-the application of chemicals that can differentiate malignant cells into normal cells. In dedifferentiated tumor cells, differentiation into normal cells is commonly induced using the following differentiation agents: retinoic acid (RA) [2], histone inhibitors, methylation inhibitors [3], peroxisome proliferator-activated receptor 
(PPAR) agonists [4, 5], or hydroxymethylglutaryl coenzyme A (CoA) reductase inhibitors [6]. Welldifferentiated liposarcoma (WDLPS) and dedifferentiated liposarcoma (DDLPS) cells can also be differentiated into adipocytes using dexamethasone, indomethacin, insulin, and IBMX. These compounds induce adipogenesis by upregulating the transcription and translation of genes involved in maintaining cancer cell stemness and adipogenic differentiation [7].

Surgical resection combined with radiotherapy and chemotherapy is the most common treatment for malignant solid tumors. However, for solid tumors with high malignancy, metastasis and recurrence can occur after radiotherapy and chemotherapy. We previously reported that radiation and chemotherapy drugs induced the formation of polyploid giant cancer cells (PGCCs) and that the daughter cells derived from PGCCs via asymmetric division had strong invasion and infiltration abilities [8, 9]. PGCCs (which had the properties of CSCs) and their daughter cells were positive for multiple normal and CSC markers. PGCCs were more tumorigenic than regular-differentiated cells in nude mice, possessed epithelialmesenchymal transition (EMT) phenotype changes, and could be induced into multiple benign lineages such as adipocytes, bone, and cartilage [10]. Lung cancer $\mathrm{NCl}-\mathrm{H} 446$ cells can be induced to differentiate into neurons, adipocytes, and bone cells in vitro [11]; cancer cells with homologous recombination defects, such as ovarian and breast cancer cells with BRCA1/2 mutations, can be induced to differentiate using poly ADP-ribose polymerase (PARP) inhibitors [12]; and thyroid cancer cells expressing the PPARY fusion protein (PPFP) can be induced to differentiate into adipocytes using pioglitazone [13].

In general, stemness is higher in cancer cells with high malignancy, which induces differentiation more easily [14]. In this study, we used $\mathrm{CoCl}_{2}$-treated HEY and MDA-MB-231 PGCCs with their daughter cells as a cell model with high metastatic ability. We confirmed that PGCCs are necessary for cancer dissemination but can be directly targeted and inhibited by a trans-differentiation approach, such as forced adipogenesis. We also highlight the crucial transcription factors that induce adipogenesis in HEY and MDA-MB-231 cells, including the well-studied PPARY and CCAAT/enhancer-binding proteins (C/EBPs) that have recently been shown to play an important role in adipocyte differentiation [15]. Recent studies reported that the $p 53$ gene deletion type of fibroblast-derived cancer cells can be induced to differentiate into adipocytes [16]. Previously, we showed that HEY cells express the wild-type $p 53(p 53+/+)$ and MDAMB-231 cells express the mutated $p 53(p 53+/)$ [17].

After induced differentiation, different $p 53$ genotypes have different levels of FABP4 expression. The wildtype $p 53$ shows higher levels of FABP4 expression and a lower degree of differentiation than that the mutant type. FABP4 negatively regulates the adipogenic differentiation of tumor cells. In PGCCs, adipogenic differentiation is negatively regulated by the P300 ubiquitination of the wild-type $p 53$ and positively regulated by the $\mathrm{P} 300$ acetylation of the mutant $p 53$. To understand the complex regulatory mechanisms in malignant tumors that can be transdifferentiated into mature adipocytes, we focused on different $p 53$ genotypes that regulate the post-translational modification of PPAR in the adipogenic differentiation of cancer cells.

\section{Methods}




\section{Cell culture in complete medium}

HEY and MDA-MB-231 cell lines were obtained from the American Type Culture Collection (ATCC; USA). HEY cells were cultured in Roswell Park Memorial Institute (RPMI)-1640 medium (Gibco, Thermo Fisher Scientific, Suzhou, China), and MDA-MB-231 cells were cultured in Dulbecco's modified Eagle's medium (DMEM; Sigma-Aldrich), supplemented with 10\% fetal bovine serum (FBS) (Gibco, Life Technologies, New Zealand) and 1\% penicillin/streptomycin (Gibco, Life Technologies, USA). Medium supplemented with serum and antibiotics was defined as complete medium. Cells cultured in complete medium were maintained in a humidified atmosphere at $37^{\circ} \mathrm{C}$ and $5 \% \mathrm{CO}_{2}$.

\section{Induction and definition of PGCCs}

The method for $\mathrm{CoCl}_{2}$ treatment was previously described in our published studies [10]. Briefly, $\mathrm{HEY}$ and MDA-MB-231 cells were cultured in T25 cell flasks containing complete medium until they reached $80-$ $90 \%$ confluence. Cells were treated with $450 \mu \mathrm{M} \mathrm{CoCl}_{2}$ (Sigma-Aldrich, St. Louis, MO, USA) for $48-72 \mathrm{~h}$, depending on their resistance to hypoxia. Most regular-sized cells were dead after $\mathrm{CoCl}_{2}$ treatment, and only a few scattered PGCCs survived. After 10-15 days, the surviving PGCCs began to produce daughter cells via asymmetric division. $\mathrm{CoCl}_{2}$ treatment was repeated three times to acquire sufficient PGCCs with daughter cells for subsequent experiments.

\section{Adipogenic differentiation of cancer cells}

Control cells and PGCCs with daughter cells were seeded into a 6-well plate and cultured in complete medium until they reached $70-80 \%$ confluence. The medium was replaced with differentiation medium A for $24 \mathrm{~h}$ (StemPro Adipogenic Differentiation Kit; Cyagen Biosciences, Suzhou, China; containing 10\% FBS, $0.5 \mathrm{mM}$ IBMX, $4 \mu \mathrm{M}$ insulin, $1 \mu \mathrm{M}$ dexamethasone, and $10 \mathrm{mM}$ rosiglitazone), then with differentiation medium $\mathrm{B}$ for another $48 \mathrm{~h}$ (a-MEM containing 10\% FBS and $4 \mu \mathrm{M}$ insulin). The cells were repeatedly cultured in $A$ and $B$ media, then harvested for subsequent experiments.

\section{Oil red 0 staining}

Oil Red O (ORO) staining was performed according to the manufacturer's instructions. HEY and MDA-MB231 control and PGCCs with daughter cells before and after adipogenic differentiation were fixed with $4 \%$ paraformaldehyde for $24 \mathrm{~h}$ at $25^{\circ} \mathrm{C}$ and then incubated with fresh ORO solution (Solarbio, Beijing, China) for $15 \mathrm{~min}$. ORO-stained intracellular lipids were quantified by measuring the optical density (OD) at 510 $\mathrm{nm}$ using a microplate reader (BioTek, USA).

\section{Western blot (WB) analysis}

Cell samples were collected and lysed in radio-immunoprecipitation (IP) assay (RIPA) lysis buffer on ice for $30 \mathrm{~min}$, then centrifuged at $14000 \mathrm{rpm}$ and $4{ }^{\circ} \mathrm{C}$ for $30 \mathrm{~min}$. The proteins were fully denatured by boiling at $100{ }^{\circ} \mathrm{C}$ for $10 \mathrm{~min}$. After the concentrations were determined, the proteins were separated on a 
$10 \%$ sodium dodecyl sulfate (SDS) polyacrylamide gel and transferred to a polyvinylidene fluoride (PVDF) membrane (Beyotime, Haimen, China). The membrane was blocked with $5 \%$ skim milk at room temperature for $2 \mathrm{~h}$, then incubated with primary antibodies. Detailed information on the antibodies is included in Supplementary Table 1. All WB assays were performed in triplicate.

\section{Flow cytometry analysis of the cell cycle}

To examine DNA content and cell cycle status, control cells and PGCCs with daughter cells before and after adipogenic differentiation were harvested. The cell pellets were resuspended in $0.1 \%$ PBS and fixed with $75 \%$ ethanol at $20^{\circ} \mathrm{C}$ for $12 \mathrm{~h}$, then permeabilized with $0.1 \%$ Triton X-100 at room temperature for 20 min. Following treatment with RNase at $37^{\circ} \mathrm{C}$ for $30 \mathrm{~min}$, the cells were incubated with propidium iodide $(50 \mu \mathrm{g} / \mathrm{mL})$ at $25^{\circ} \mathrm{C}$ for $15 \mathrm{~min}$. Cell cycle was analyzed by flow cytometry (BD FACSCalibur ${ }^{\mathrm{TM}}, \mathrm{BD}$ Biosciences). The percentage of cells in the $\mathrm{G} 1, \mathrm{~S}$, and $\mathrm{G} 2$ phases were quantified using BD CellQuestä version 5.1 software (BD Biosciences).

\section{Quantitative real-time PCR}

Total RNA was extracted using the TRIzol/chloroform method, and RNA was precipitated from the aqueous phase using isopropyl alcohol. RNA was reverse transcribed using a HighCapacity RNA to cDNA kit (TIAGEN, KR116, Beijing, China). Quantitative real-time PCR (qPCR) was performed using a Roche LightCycler 480 Real-Time PCR System. The qPCR conditions included $2 \mu \mathrm{L}$ of cDNA diluted in nuclease-free water, $50 \mathrm{ng}$ of total RNA, $25 \mu \mathrm{L}$ of Universal PCR Master Mix (CWBIO, 0957), and $1 \mu \mathrm{L}$ of $10 \mu \mathrm{M}$ forward primer. Nuclease-free water was added to $1 \mu \mathrm{L}(10 \mu \mathrm{M})$ reverse primer to reach a final volume of $50 \mu \mathrm{L}$. The amplification procedure was as follows: initial denaturation at $95^{\circ} \mathrm{C}$ for $15 \mathrm{~min}$, followed by 45 cycles of $95^{\circ} \mathrm{C}$ for $15 \mathrm{~s}, 60^{\circ} \mathrm{C}$ for $1 \mathrm{~min}$, and $40^{\circ} \mathrm{C}$ for $30 \mathrm{~s}$. $\beta$-actin was used as the reference gene for the quality and quantity of cDNA. Detailed primer sequences are shown in Supplementary Table 2.

\section{Transient siRNA transfection}

p53 was knocked down by transient siRNA transfection. The siRNA oligonucleotides were synthesized by Gene-pharma (Shanghai, China) and included three siRNA interference sequences, one positive control sequence (GAPDH), one negative control (NC) sequence, and one mock control ( $M C$, transfection reagent only). Three $p 53$ transfection sequences, 339,886 , and 985 , were used to inhibit the expression of $p 53$ (Supplementary Table 3). Control cells and PGCCs with daughter cells grown in 6-well plates at $60-80 \%$ confluence were transfected with NC siRNA, p53-siRNA, MC, and GAPDH-siRNA using Lipofectamine 2000 (Invitrogen, Carlsbad, CA, USA) and 1× Opti-MEM (Gibco, USA) according to the manufacturer's instructions [siRNA:lipo $=20: 1$ (pmol:uL)]. After transfection for $48 \mathrm{~h}$, WB was performed to detect the efficiency of the target protein inhibition.

\section{P300 histone acetyltransferase activity assay}


P300 histone acetyltransferase (HAT) activity assay was performed using the P300 HAT spectrophotometry quantitative detection kit (GenMed Scientific Inc., USA) to test the differences in P300 HAT activity before and after adipogenic differentiation in vitro. Histone $\mathrm{H} 3$ peptide was used as the substrate for detection. HEY and MDA-MB-231 cells were treated with sodium butyrate for $48 \mathrm{~h}$. Nuclear extracts were harvested as described above and subjected to the assays. Briefly, each nuclear extract was incubated with $100 \mu \mathrm{M}$ acetyl-CoA and $1 \times$ HAT assay buffer on a histone H3-precoated enzyme-linked immunosorbent assay plate for $30 \mathrm{~min}$. P300 transfers the acetyl group of acetyl-CoA to the histone peptide, releasing sulfhydryl-CoA, which then reacts with Ellman's reagent to produce a change in the absorbance peak. After several washes with PBS, acetylated histones were detected using the HAT assay kit according to the manufacturer's protocol. Fluorescence intensity was detected using a multifunction microplate reader (BioTek) at $412 \mathrm{~nm}$. HAT activity was calculated using the following equation: \{[sample reading-background reading] $\times 0.1$ (system capacity; $\mathrm{mL}$ ) $\times$ sample dilution factor $\div \div[0.01$ (sample capacity; $\mathrm{mL}) \times 13.6$ (millimolar absorbance coefficient) $\times 15(\mathrm{~min})]=$ unit $/ \mathrm{mL} \div$ (sample protein concentration) $\mathrm{mg} / \mathrm{mL}=$ unit $/ \mathrm{mg}$

\section{A485 inhibitor treatment}

A485 is a potent and selective catalytic inhibitor of p300/CBP [18]. Control cells and PGCCs with daughter cells before and after adipogenic differentiation were cultured in a 6-well plate until they reached $80 \%$ confluence. Each well was then treated with $10 \mu \mathrm{M}$ A485 (Selleck, USA) for $24 \mathrm{~h}$.

\section{Cell counting kit-8 (CCK8) assay}

Cell viability was evaluated using the CCK8 assay. Control cells and PGCCs with daughter cells before and after adipogenic differentiation were seeded at 2,000 cells per well in 96-well plates (three replicate wells per group) and incubated for $12 \mathrm{~h}$. Wells containing medium alone were used as controls. The cells in treatment wells were treated with different concentrations of A485 and cultured for various time intervals. After treatment, $10 \mu \mathrm{L}$ of CCK8 (Dojndo, Japan) was added to each well and incubated for $2 \mathrm{~h}$. OD was measured using a Bio-Rad microplate reader at $450 \mathrm{~nm}$ and was calculated from the average value of readings after subtracting the average value of the control.

\section{Co-IP and mass spectrometry (MS)}

Co-IP was performed using the Pierce Classic Magnetic IP/Co-IP Kit (Thermo Fischer Scientific, 87787, USA) according to the manufacturer's instructions. Control cells and PGCCs with daughter cells before and after adipogenic differentiation were lysed using IP lysis buffer (Thermo Fisher Scientific) containing halt protease and phosphatase inhibitor cocktail (1:100 dilution) for $30 \mathrm{~min}$, then centrifuged at 14000 rpm for $10 \mathrm{~min}$. The supernatant was incubated with rabbit anti-PPARy monoclonal antibody and mouse anti-SIRT1 monoclonal antibody $(1: 50)$ at $4{ }^{\circ} \mathrm{C}$ overnight. Normal rabbit IgG (Beyotime, Shanghai, China) was used as the NC. Pre-washed protein A/G agarose beads (Thermo Fisher Scientific) were added to each IP tube and incubated at $4{ }^{\circ} \mathrm{C}$ for $2 \mathrm{~h}$. After washing and centrifugation, the immunoprecipitates were examined by WB. MS analysis of Co-IP substrates was performed using tandem MS (MS/MS) in Q 
ExactiveTM Plus (Thermo) coupled online to an ultra-performance liquid chromatography system for the acquisition of MS/MS data. The peptides were identified and quantified using Proteome Discoverer 1.3. The peptide confidence was set at a high value, and the peptide ion score was set at $>20$.

\section{Immunocytochemical (ICC) and immunohistochemical (IHC) staining}

For ICC staining, cells grown on coverslips were washed with sterile PBS, then fixed with cold methanol for 30 min. After treating with $0.3 \%$ endogenous peroxidase inhibitor (Zhongshan Inc., Beijing, China) for 15 min, the cells were incubated with 1.5\% normal goat serum (Zhongshan Inc., Beijing, China) for 20 min to block non-specific protein binding. After incubation with primary antibodies at $4{ }^{\circ} \mathrm{C}$ overnight, biotinylated goat anti-mouse/rabbit IgG (Zhongshan Inc., Beijing, China) and horseradish peroxidaselabeled streptomycin (Zhongshan Inc., Beijing, China) were added to the slides for 20 and 15 min, respectively. For IHC staining, paraffin-embedded tissue sections were deparaffinized in xylene and dehydrated in a series of gradient alcohol solutions. Antigen retrieval was carried out by adding citrate buffer solution (Origene, Wuxi, China) at $160{ }^{\circ} \mathrm{C}$ for 1-2 min. After the sections were incubated with primary antibodies and reacted with biotinylated goat anti-rabbit IgG antibody for $20 \mathrm{~min}$, the signal was detected using the labeled streptavidin-biotin system in the presence of the chromogen 3,3diaminobenzidine or alkaline phosphatase. Nuclei were counterstained with hematoxylin.

\section{Wound healing assay}

Control cells and PGCCs with daughter cells before and after adipogenic differentiation were seeded into 12-well plates $\left(1 \times 10^{5}\right.$ per well, three replicate wells per group) and cultured until they reached $100 \%$ confluence. Sterile pipette tips were then used to uniformly scratch the monolayer cells vertically to form wound tracks. After rinsing with PBS to remove floating cells, the wells were cultured in serum-free medium. The migration ability was evaluated by photographing the wound area at 0,12 , and $24 \mathrm{~h}$ for $\mathrm{HEY}$ and at 0,16 , and $32 \mathrm{~h}$ for MDA-MB-231 cells at the same scratch position. Image J software was used to outline the migration area and calculate the wound-healing index according to the following formula: [(wound area at $0 \mathrm{~h}$ ) - (wound area at indicated time)]/(wound area at $0 \mathrm{~h}$ ). A high score indicated strong migration ability.

\section{Cell migration and invasion assays}

Control cells and PGCCs with daughter cells before and after adipogenic differentiation were washed three times with FBS-free medium and counted using an automated cell counter (Invitrogen, CA, USA). Cell migration and invasion were assessed using transwell migration and invasion assays $(8 \mu \mathrm{m}$; Corning Inc.), respectively. For the migration assay, cells ( $5 \times 10^{4}$ cells per insert) in $200 \mu \mathrm{L}$ medium without FBS were added to the upper chamber. For the invasion assay, cells $\left(2 \times 10^{5}\right.$ cells per insert) in $200 \mu \mathrm{L}$ of medium without FBS were added to the upper chamber coated with Matrigel. Medium containing $20 \%$ FBS was added to the lower chamber, and the 24-well plates were incubated for an additional $12-24 \mathrm{~h}$ at $37^{\circ} \mathrm{C}$. Then, the cells were fixed in methanol for $30 \mathrm{~min}$ and stained with $0.1 \%$ crystal violet for $30 \mathrm{~min}$. Migration and invasion abilities were assessed by counting the number of cells per field. Photos were 
taken at 100x magnification, and at least five different fields were counted. Three independent experiments were performed.

\section{Plate clone formation assay}

Control cells and PGCCs with daughter cells before and after adipogenic differentiation were counted. Cell suspensions ( $2 \mathrm{~mL} /$ well) with 30,60 , and 120 cells were cultured in a 12-well plate, and the plates were incubated for at least 2 weeks at $37^{\circ} \mathrm{C}$. Incubation was stopped when a white cell clone was visible. The cell clones were washed with PBS and fixed with cold methanol for $30 \mathrm{~min}$. After staining with $0.1 \%$ crystal violet for $30 \mathrm{~min}$, the number of cell clone groups per well was counted under a microscope (the number of cells in a single clone should be more than 50 ), and the efficiency of colony formation was calculated using the following formula: formation efficiency = (number of clones/number of cells inoculated).

\section{Animal Experiments}

Forty 4- to 6-week-old female BALB/c NU/NU nude mice (20 for HEY and 20 for MDA-MB-231) were obtained from Beijing Weitonglihua Co. Ltd. The 20 nude mice in HEY and MDA-MB-231 were divided into four groups (five mice per group), and each group was injected with $200 \mu \mathrm{L}$ of tumor cell suspension ( $1 \times 10^{7}$ cells) containing one of the following: (i) control cells, (ii) control cells after adipogenic differentiation, (iii) PGCCs with their daughter cells, or (iv) PGCCs with their daughter cells after adipogenic differentiation. Starting from day 5 after HEY cell inoculation and day 15 after MDA-MB-231 cell inoculation, the tumor mass could be touched, and the size of the tumor was measured every other day. The animals were sacrificed 30 days after inoculation. Paraffin-embedded tumor tissues were used for hematoxylin \& eosin (H\&E) staining and IHC staining, and fresh tumor tissues were used for WB analysis. The animal study was approved and supported by the Institutional Animal Care and Use Committee of the Tianjin Union Medical Center.

\section{H\&E staining}

Tumor sections were fixed in formalin for $24 \mathrm{~h}$ at room temperature and embedded in paraffin, then $4-\mu \mathrm{m}-$ thick sections were made. The tissue sections were subsequently deparaffinized in xylene for $12 \mathrm{~h}$ at 75

${ }^{\circ} \mathrm{C}$ and rehydrated using a descending ethanol series. Sections were stained with $0.2 \%$ hematoxylin (Baso, Zhuhai, Guangzhou, China) at room temperature for $1 \mathrm{~min}$ and with $0.5 \%$ eosin for $2 \mathrm{~min}$. After staining, the sections were dehydrated and mounted on coverslips.

\section{Statistical Analysis}

Data are presented as the mean \pm SEM. Statistical analysis and graphs were generated using SPSS 22 software (SPSS Inc., Chicago, USA) and GraphPad Prism software. Statistical analyses were performed as indicated in the figure legends. In vitro studies were biologically repeated at least three times, and statistical analysis was performed using ANOVA and unpaired t-test. The number of animals in each 
experiment is indicated in the figure legends. In vivo statistical analysis was performed using the KruskalWallis test corrected for multiple comparisons. Statistical significance was set at $P<0.05$. Error bars represent \pm S.D., and $p$-values represent comparisons with each control $\left({ }^{\star \star \star} P<0.001 ; * \star P<0.005 ; * P<\right.$ 0.05 ; NS, non-significant).

\section{Results}

\section{$\mathrm{CoCl}_{2}$ can induce the formation of PGCCs}

HEY and MDA-MB-231 cells were treated with $\mathrm{CoCl}_{2}(450 \mu \mathrm{M}$ for $48 \mathrm{~h})$. Most of the regular-sized tumor cells died, and only a small number of cells with large nuclei (PGCCs) survived (Figures 1A-a, -c). After culturing in complete medium without $\mathrm{CoCl}_{2}$ for 10-15 days, the PGCCs generated daughter cells via asymmetric division. The PGCCs were three times larger than the regular control cells (Figures 1A-b, -d) and the PGCCs with daughter cells gained a mesenchymal phenotype with increased expression of the CSC markers CD44 and CD133 [10].

\section{PGCCs can differentiate into adipocytes}

HEY and MDA-MB-231 control and PGCCs with daughter cells were cultured in adipogenic differentiation medium containing rosiglitazone, dexamethasone, IBMX, and insulin for 7 days. When comparing the cell groups cultured in adipogenic differentiation media, PGCCs with daughter cells had more vacuoles in their cytoplasm (Figures 1B-a and 1C-a) than the controls (Figures 1B-C and 1C-C). All cell groups that were not cultured in differentiation media (HEY and MDA-MB-231 PGCCs with daughter cells, Figures 1B$\mathrm{b}$ and $1 \mathrm{C}-\mathrm{b}$, and controls, Figures $1 \mathrm{~B}-\mathrm{d}$ and $1 \mathrm{C}-\mathrm{d}$ ) had no vacuoles. ORO staining showed more red lipid droplets in the PGCCs with daughter cells (Figures 1D-a, -b and 1E-a, -b) than in the controls (Figures 1D-c, $-d$ and $1 E-c,-d)$. ORO staining in a 6-well plate also showed that after adipogenic differentiation, intracellular lipid accumulation increased more with time in the PGCCs with daughter cells than in the controls (Figure 1F). The statistical results are shown in Figure 1G.

\section{Infiltration and invasion abilities in control cells and PGCCs with daughter cells before and after adipogenic differentiation}

Cell invasion assays were performed using Matrigel-coated transwell inserts. The invasive (Figures S1AS1B) and migratory abilities (Figures S1C-S1D) in cells cultured in adipogenic differentiation media were lower than those in cells cultured in complete media. Statistical analysis confirmed this result. PGCCs with daughter cells in adipogenic differentiation media had the lowest number of invasive and migratory cells among all the cell groups (Figure S1E). Migration ability was also measured by wound-healing assay in HEY and MDA-MB-231 control and PGCCs with daughter cells before and after adipogenic differentiation. Without adipogenic differentiation, the migration ability of PGCCs with their daughter cells was stronger than those of the controls. However, migration abilities decreased in both the control and PGCCs with daughter cells after adipogenic differentiation (Figures S1F-S1G). A plate cloning assay was used to detect the cell proliferative ability. The numbers of clones formed in HEY and MDA-MB-231 
PGCCs with daughter cells after adipogenic differentiation were significantly lower than those of the corresponding cells without adipogenic differentiation (Figures S1H-S1I). Migration, invasion, and proliferation abilities decreased when cells were cultured in adipogenic differentiation medium.

\section{Flow cytometric analysis of control and PGCCs with daughter cells before and after adipogenic differentiation}

HEY and MDA-MB-231 control and PGCCs with daughter cells were cultured in adipogenic differentiation media for $168 \mathrm{~h}$ and used for DNA content and cell cycle analysis. Cell proliferation and differentiation are regulated by the cell cycle, which is divided into a series of phases based on the chromosome content of the cell. We previously reported that the cell cycle was arrested at the G2/M phase in PGCCs with daughter cells [17]. After HEY and MDA-MB-231 cells were treated with $\mathrm{CoCl}_{2}$, as shown in Figures 2A-2D, PGCCs with daughter cells had a greater number of cells arrested in the G2/M phase (HEY PGCCs: 9.25\%; MDA-MB-231 PGCCs: 11.88\%) compared with the control cells (HEY control cells: 7.14\%; MDA-MB-231 control cells: 9.34\%). This indicates that $\mathrm{CoCl}_{2}$ induced cell cycle arrest in the $\mathrm{G} 2 / \mathrm{M}$ phase in HEY and MDA-MB-231 PGCCs with daughter cells. Seven days after inducing adipogenic differentiation, the second cell cycle appeared in HEY and MDA-MB-231 PGCCs with daughter cells. There were more cells in the G1 phase in the second cell cycle (HEY PGCCs with daughter cells: 94.33\%; MDA-MB-231 PGCCs with daughter cells: $87.92 \%$ ), indicating that differentiation occurred in PGCCs with daughter cells after inducing adipogenic differentiation (Figures $2 \mathrm{~A}$ and $2 \mathrm{C}$ ). The proportion of cells in the S and G0/G1 phases in HEY and MDA-MB-231 control cells were higher after adipogenic differentiation than before adipogenic differentiation (Figures 2B and 2D), indicating that these cells exhibited limited growth potential after adipogenic differentiation. The statistical results are shown in Figure 2E.

\section{Expression of adipogenic differentiation-related proteins}

WB was performed to compare the expression of adipogenic differentiation-related proteins in control cells and PGCCs with daughter cells before and after adipogenic differentiation. The total CREB expression was lowest in PGCCs with daughter cells after adipogenic differentiation. CREB is activated by phosphorylation at serine 133 after inducing differentiation. On the other hand, the expression levels of phospho-CREB(Ser133), PPARY, C/EBPa, C/EBPB, and FABP4 were highest in PGCCs with daughter cells after adipogenic differentiation (Figures $2 \mathrm{~F}$ and $2 \mathrm{G}$ ). The results of $\mathrm{qPCR}$ showed that the expression levels of C/EBPa, PPARY, and FABP4 mRNA were higher in HEY and MDA-MB-231 control and PGCCs with daughter cells after adipogenic differentiation compared with those in the corresponding cells before adipogenic differentiation, and the differences for $\mathrm{C} / \mathrm{EBPa}(P=0.0364, P=0.0404$ for HEY; $P=0.0006$, $P=0.0001$ for MDA-MB-231; Figures 2D-a, $-d)$, PPARY $(P=0.0116, P=0.0485$ for HEY; $P=0.0028, P=0.0008$ for MDA-MB-231; Figures 2D-b, $-\mathrm{e})$, and FABP4 $(P=0.013, P=0.0055$ for HEY; $P=0.0385, P=0.0309$ for MDAMB-231; Figure $2 \mathrm{H}$ ) were statistically significant.

\section{Different p53 genotype regulated FABP4 expression}


We previously reported that HEY cells have the wild-type $p 53(p 53+/+)$ and MDA-MB-231 cells have the mutated $p 53(p 53+/-)$ [17]. Figure 3A-a shows that the expression level of FABP4 in HEY cells increased after adipogenic differentiation. There were no obvious changes in FABP4 expression in MDA-MB-231 cells before and after adipogenic differentiation (Figure 3A-b). The statistical results are shown in Figures $3 A-c$ and $-d$. ICC staining showed that nuclear expression of FABP4 was higher in all cell groups after adipogenic differentiation (Figures 3B-a, $-\mathrm{C}$ and $3 \mathrm{C}-\mathrm{a},-\mathrm{c}$ ) than in the corresponding cells without adipogenic differentiation (Figures 3B-b, $-d$ and $3 C-b,-d$ ). qPCR results also confirmed that FABP4 mRNA expression increased in both HEY and MDA-MB-231 cells after adipogenic differentiation compared with those in the corresponding cells without adipogenic differentiation (Figures $2 \mathrm{H}-\mathrm{c}$, $-\mathrm{f}$ ). Different genotypes of $p 53$ play an important role during adipogenic differentiation of MSCs and cancer cells. To study the relationship between P53 and FABP4, P53 was knocked down in HEY and MDA-MB-231 control and PGCCs with daughter cells after the cells had been induced to adipogenic differentiation for $168 \mathrm{~h}$. After P53 knockdown, WB showed that the expression of FABP4 decreased in HEY control and PGCCs with daughter cells and increased in MDA-MB-231 control and PGCCs with daughter cells, compared with the corresponding cells before P53 knockdown (Figures 3D-3G). The statistical results are shown in Figures $3 A-c$ and $-d$. ORO staining showed that before $p 53$ knockdown, the degree of differentiation was significantly lower in the wild-type $p 53 \mathrm{HEY}$ cells than in the mutant $p 53 \mathrm{MDA}-\mathrm{MB}-231$ cells (Figures $3 \mathrm{H}-\mathrm{a}$, $-b$ and $3 \mathrm{l}-\mathrm{a},-\mathrm{b})$. The statistical results are shown in Figure 3J. After knocking down $p 53$, the degree of differentiation of wild-type $p 53 \mathrm{HEY}$ cells was significantly higher than that of the mutant $p 53 \mathrm{MDA}-\mathrm{MB}$ 231 cells (Figures $3 \mathrm{H}-\mathrm{c},-\mathrm{d}$ and $3 \mathrm{I}-\mathrm{c},-\mathrm{d}$ ). The statistical results are shown in Figure 3J.

\section{The phosphorylation of PPARY in HEY and MDA-MB-231 was significantly upregulated at an early stage of adipogenic differentiation then downregulated}

Previous studies have shown that PPARy can be phosphorylated by the MEK/ERK signaling pathway [19]. ICC staining showed that nuclear expression of PPARY was higher in HEY and MDA-MB-231 control and PGCCs with daughter cells after adipogenic differentiation (Figures $4 A-a,-c$ and $4 B-a,-c$ ) than in the corresponding cells without adipogenic differentiation (PGCCs with daughter cells, Figures 4A-b, -d; control cells, Figures 4B-b, -d). Since PPARy is a master regulator in the adipogenic differentiation of PGCCs with daughter cells, we assessed the ability of ERK to induce PPARY phosphorylation. As shown in Figures 4C-4D, phospho-ERK(Thr202/Tyr204) expression in HEY control and PGCCs with daughter cells began to decline at $72 \mathrm{~h}$ after inducing adipogenic differentiation, with no significant changes in total ERK levels. Expression of phospho-PPARY(Ser112) started at $48 \mathrm{~h}$, then steadily decreased at $72 \mathrm{~h}$. Expression of phospho-CREB(Ser133)-PPARY-FABP4 started at $48 \mathrm{~h}$ and subsequently maintained a stable expression level. PPARy expression was initiated by phospho-CREB (Ser133), and PPARY phosphorylation levels were regulated by phosphorylated ERK during the adipogenic differentiation of HEY control and PGCCs with daughter cells (Figures 4C-4D). This was also observed in the MDA-MB-231 cells (Figures 4E-4F). Phospho-ERK (Thr202/Tyr204) expression in MDA-MB-231 control and PGCCs with daughter cells began to decline at $73 \mathrm{~h}$, which was accompanied by an increase in total ERK. PhosphoPPARY (Ser112) was not detected because of its relatively low expression. Expression of phospho-CREB 
(Ser133)-PPARy started at $24 \mathrm{~h}$ and subsequently maintained a stable expression level. FABP4 expression began to increase at $72 \mathrm{~h}$ but decreased at $168 \mathrm{~h}$ (Figures 4E-4F).

\section{Phosphorylation level of PPARY in the adipogenic differentiation of HEY and MDA-MB-231 before and after si-P53 transfection}

PPARy expression gradually increased after inducing adipogenic differentiation. Both the protein levels and the phosphorylation levels of PPARy were correlated with the expression of P53-ERK-CREB during differentiation. Transfection with siRNA inhibited the expression of P53 during adipogenic differentiation in HEY and MDA-MB-231 cells. Blocking the wild-type $p 53(p 53+/+)$ in HEY PGCCs with daughter cells undergoing adipogenic differentiation did not lead to a significant change in the PPARY protein expression and phosphorylation compared to the negative groups, but a slight decrease in CREB and ERK phosphorylation was detected using phospho-CREB(Ser133) and phospho-ERK(Thr202/Tyr204) antibodies (Figure 5A). In addition, ORO staining showed that the degree of differentiation in HEY PGCCs with daughter cells was higher after P53 knockdown (Figures 5E-c, -d). The statistical results are shown in Figure 5E-e. In HEY control cells, after adipogenic differentiation, PPARY showed a significant increase with phospho-CREB(Ser133) expression compared to the negative groups, while phospho-PPARY(Ser112) and phospho-ERK(Thr202/Tyr204) expression slightly decreased (Figure 5B). ORO staining also showed that the degree of differentiation in HEY control cells was higher after P53 knockdown (Figures 5E-a, -b). The statistical results are shown in Figure 5E-e. When blocking the wild-type $p 53(p 53+/+)$ in MDA-MB231 PGCCs with daughter cells undergoing differentiation (Figure $5 C$ ) and in MDA-MB-231 control cells (Figure 5D) after adipogenic differentiation, PPARy expression was downregulated with a decrease in phospho-CREB(Ser133) compared with the negative groups, while phospho-PPARY(Ser112) and phosphoERK(Thr202/Tyr204) expression were significantly upregulated. ORO staining showed that the degree of differentiation in MDA-MB-231 control (Figures 5F-a, -b) and PGCCs with daughter cells (Figures 5F-c, -d) were higher after P53 knockdown. The statistical results are shown in Figure 5F-e.

\section{Acetylation of PPARY in HEY and MDA-MB-231 before and after adipogenic differentiation}

PPARy is regulated by a series of post-translational modifications [20]. The effect of acetylation on PPARY is mainly mediated by cell senescence and regulation of adipocyte metabolism. Many studies have confirmed that the deacetylation of PPARY by SIRT1 can downregulate the expression of PPARY and inhibit adipogenic differentiation [21]. PPARy acetylation promotes lipid synthesis. When the conserved lysine motif (K154/155) of PPARY1 is acetylated, it can promote lipid synthesis in ErbB2-positive breast cancer cells [22]. IP combined with WB was used to detect the post-translational acetylation level of PPARY in HEY and MDA-MB-231 control and PGCCs with daughter cells before and after adipogenic differentiation. Using PPARY IP-level antibodies, cell pellets were collected before and after adipogenic differentiation for IP, as shown in Figures 6A and 6B. We successfully pulled down the PPARy protein after adipogenic differentiation of HEY control and PGCCs with daughter cells, and we used WB to detect broad-spectrum acetylation at the lysine site. We found that after adipogenic differentiation, the PPARY lysine site was acetylated, and the level of modification in HEY control and PGCCs with daughter cells 
was higher after adipogenic differentiation (Figures 6C and 6D). PPARy protein underwent acetylation during adipogenic differentiation, which was also observed in MDA-MB-231 control and PGCCs with daughter cells (Figures 6E-6H). The acetylation level of PPARy increased most significantly after adipogenic differentiation of MDA-MB-231 PGCCs with daughter cells (Figures 6F and 6H). P300 expression increased after HEY and MDA-MB-231 adipogenic differentiation (Figure 6I), and the difference was statistically significant (Figure 6J). In vitro HAT assay was used to detect P300 acetyltransferase activity and showed that HEY and MDA-MB-231 control and PGCCs with daughter cells had increased P300 activity after adipogenic differentiation (Figure 6K).

\section{P300-P53 regulate the acetylation of PPARY in adipogenic differentiation of HEY and MDA-MB-231 cells}

P300 is an HAT that activates genes by attaching acetyl groups to histones. Mutual regulation between P300 and P53 has previously been reported [23]. When P300 acetylates P53, P53 becomes activated and positively regulates $\mathrm{P} 300$. At the same time, $\mathrm{P} 300$ can regulate the ubiquitin-like degradation of P53. The acetylation and ubiquitin-like modification of P53 occur at the same lysine site [24] and show a competitive relationship. In the present study, P53 and P300 were immunoprecipitated, and WB was used to analyze their interaction with PPARY in the adipogenic differentiation of HEY and MDA-MB-231 cells. The results showed an interaction among these three proteins (Figure 7).

We detected the expression of P300 when P53 was knocked down. Transfection with siRNA to inhibit the expression of P53 (Figure 8A) showed that P53 knockdown markedly attenuated P300 expression levels in both HEY and MDA-MB-231 PGCCs (Figures 8B-8E). In HEY cells undergoing adipogenic differentiation, blocking wild-type $p 53(p 53+/+)$ eliminated P300 expression, whereas in HEY PGCCs with daughter cells, the acetylation of PPARY was upregulated compared with the negative groups (Figure 8B). In HEY control cells after adipogenic differentiation, the acetylation of PPARy showed no significant change compared to the NC cells (Figure 8C). HEY cells that express wild-type $p 53(p 53+/+)$ have a negative regulatory relationship between P300 and PPARY acetylation levels after adipogenic differentiation. MDA-MB-231 cells that express mutation-type $p 53(p 53+/-)$ have a positive regulatory relationship between P300 and PPARy acetylation levels after adipogenic differentiation. As shown in Figures 8D-8E, blocking mutation P53 expression in MDA-MB-231 control and PGCCs with daughter cells eliminated P300 expression, and in adipogenic differentiation, the acetylation of PPARY decreased compared with that of the NC groups. The results and detailed statistics are shown in Fig 8F.

A485 is a potent and selective catalytic inhibitor of p300/CBP [18]. The effect of A485 on the viability of HEY and MDA-MB-231 control and PGCCs with daughter cells was analyzed using a CCK8 assay (Figure 9F). Based on these results, $24 \mathrm{~h}$ pre-treatment with $10 \mu \mathrm{M}$ A485 was chosen for further studies. As shown in Figures 9A-9D, the acetylation of PPARY and of P53 at Lys-382 increased in HEY and MDA-MB231 cells after adipogenic differentiation. However, SUMO-P53 levels also increased with the increase in P300 after adipogenic differentiation (Figures 9A-9B), suggesting that P300 may be a negative factor for wild-type $p 53(p 53+/+)$ in HEY cells. IP and WB analyses showed a decrease in PPARy acetylation levels, accompanied by an increase in P53 acetylation levels in HEY cells (Figures 9A-9B and 9E-a, -b, -e, -f) 
before and after adipogenic differentiation with the P300 inhibitor A485. PPARY acetylation was negatively modulated by wild-type P53 (+/+) in HEY cells (Figures 9A-9B), forming a P300-P53 (+/+)-acePPARy negative feedback loop, and blocking P300 caused wild-type P53 expression and an increase in ace-PPARy expression (Figures 9A-9B and 9E-a, -b, -e, -f). IP and WB further showed that A485 treatment led to a decrease in the acetylation levels of PPARY and P53 in MDA-MB-231 cells (Figures 9C-9D and 9E$c,-d,-g,-h)$ before and after adipogenic differentiation. PPARy acetylation was positively modulated by mutation type P53 (+/-) in MDA-MB-231 cells (Figures 9C-9D), forming a P300-P53 (+/-)-ace-PPARY positive feedback loop, and blocking mutated P53 decreased the expression of ace-PPARY (Figures 9C-9D and $9 \mathrm{E}-\mathrm{c},-\mathrm{d})$.

\section{Adipogenic differentiation of cancer cells in vivo}

To translate the in vitro findings in vivo, xenograft ovarian and breast cancer models were established by subcutaneous injection of HEY (Figure 10) and MDA-MB-231 cells (Figure 11) into BALB/c nude mice. The mice were divided into four treatment groups: (i) control cells, (ii) control cells after adipogenic differentiation, (iii) PGCCs, and (iv) PGCCs after adipogenic differentiation. On day 30, all mice were sacrificed, and the xenograft tumors were removed and analyzed. The xenograft tumor model exhibited a change in tumor volume before and after differentiation (Figures 10B and 11B). The average volumes of xenograft tumors were significantly smaller in the in vitro-differentiated groups than in the undifferentiated (UD) groups (Figures 10A and 11A). Tumor growth curves show that tumors in the in vitro-differentiated group grew markedly slower than those in the UD groups (Figures 10C and 11C). H\&E staining was performed to visualize morphology, and histological analysis revealed dense cancer cells in the UD groups. Compared with the UD groups, the in vitro-differentiated groups had more lipid droplets distributed in their tissues and had cells that became round and loosely bound (Figures 10E and 11E). Adipogenic differentiation was confirmed by FABP4 expression (Figures 10D and 11D) and IHC staining (Figures $10 \mathrm{H}$ and $11 \mathrm{H}$ ). Immunostaining was performed to detect the human-derived marker vimentin and confirm the human origin of these cells (Figures 10F and 11F). Notably, when analyzing the Ki-67 IHC staining (Figures 10G and 11G), we observed that in vitro adipogenic differentiation exhibited a tumor infiltration zone with a benign, segmental differentiation morphology. The in vitro differentiation model revealed that cancer cells successfully differentiated into mature adipocyte lineages under induction of adipocyte differentiation.

\section{Discussion}

In this study, we reported the adipogenic differentiation of cancer cells. PGCCs undergo EMT to obtain a mesenchymal cell phenotype and stem cell characteristics, which promotes the trans-differentiation of cancer cells. We explored the relevant mechanisms of PGCC adipogenic differentiation. The first part of the experiment confirmed that HEY and MDA-MB-231 cells were successfully induced to differentiate in vitro. The second part of the experiment confirmed that the P53-ERK-CREB-PPARY-CEBPa/ $\beta-F A B P 4$ pathway regulates the adipogenic differentiation process of HEY and MDA-MB-231 control and PGCCs with daughter cells. After adipogenic differentiation, PPARy is regulated by post-translational 
modifications. The third part of the experiment confirmed that the adipocytes produced by PGCCs after adipogenic differentiation are mature adipocytes and will no longer undergo dedifferentiation.

PPARY is a master regulator of adipogenic differentiation [25]. It induces the expression of C/EBPa during adipogenic differentiation, thereby dramatically stimulating the induction of adipocyte genes [26]. In our study, PPARy expression gradually increased after inducing differentiation, and both the protein levels and the phosphorylation levels of PPARy were correlated with the expression of P53-ERK-CREB during differentiation. The transition between cell proliferation and cell differentiation during adipogenic differentiation is a tightly regulated process in which both cell cycle regulators and differentiating factors interact, creating a cascade of events leading to the commitment of the cells to the adipocyte phenotype [27]. Growth-arrested preadipocytes undergo several rounds of the cell cycle before terminally differentiating into adipocytes, suggesting that cross-talk may exist between the cell cycle or the cell proliferation machinery and the factors controlling cell differentiation. PPARY ligand production is tightly linked to clonal expansion during the initiation of adipogenic differentiation. Post-translational modification of chromatin histones is a key mechanism of transcriptional regulation [28]. Protein phosphorylation is a common post-translational modification that regulates a wide range of signaling pathways involved in differentiation, apoptosis, proliferation, gene regulation, and metabolism [29]. PPARy is a short-lived protein [30], and it has been shown to be regulated by a series of post-translational modifications [31]. Studies have found that PPARy has a variety of post-translational modifications, including phosphorylation, ubiquitination, SUMO-mediated modification, acetylation, and nitrosylation [32]. The phosphorylation of PPARY is the most well studied. It involves mitogen-activated protein kinases (MAPKs), cyclin-dependent kinase 5 (CDK5), and AMP-activated protein kinase (AMPK). Different kinases phosphorylate modified proteins to produce different biological functions. Studies have shown that during the differentiation of 3T3-L1 adipocytes, CDK9-mediated PPARY is highly phosphorylated, indicating that CDK9 can mediate PPARy phosphorylation, enhance the transcriptional activity of PPARY, and promote adipogenic differentiation and lipid synthesis [33]. Our study confirmed that adipogenic differentiation of PGCCs activates the ERK pathway, which phosphorylates PPARY, reduces the expression of PPARY mRNA and protein, and inhibits adipogenic differentiation. The phosphorylation level of PPARy protein at Serine 112 gradually decreased at the early adipocyte differentiation stage, while the downstream FABP4 protein expression gradually increased, enabling tumor cells to acquire the adipocyte phenotype. Helenius et al. also confirmed that phosphorylation inhibits the ability of PPARY to promote adipogenic differentiation [34]. Phosphorylation of PPARY2 at the $\mathrm{N}$-terminal serine residue 112 reduces its transcriptional activity, promotes ubiquitination on lysine 107, and further reduces its ability as a transcriptional activator [35]. After inducing adipogenic differentiation of PGCCs, the regulatory effect between phosphorylation and ubiquitination of PPARY is awaiting further study.

The tumor suppressor gene $p 53$ is functionally involved in cell cycle control, apoptosis, and genomic stability and is mutated and inactivated in most human cancers. A hallmark of virtually all cancers is the dysregulated expression or functioning of pRB or P53 [16]. There are several p53 gene mutations in human tumors, including wild-type $(p 53+/+)$, knockdown ( $p 53+/-)$, and deletion ( $p 53-/-)$ [36]. Although $p 53$ is one of the most well-described genes, its role in adipocytes is poorly understood. Regulation of 
PPARy expression by P53 depends on the $p 53$ genotype. Our experiments confirmed that the P53-ERKCREB pathway regulates the activation and phosphorylation of PPARY during the adipogenic differentiation of HEY and MDA-MB-231 control and PGCCs with daughter cells. The level of FABP4 expression in the $p 53$ wild-type is higher than that in the $p 53$ mutant type, but the degree of adipogenic differentiation in the $p 53$ wild-type is lower than that in the $p 53$ mutant type. FABP4 negatively regulates the adipogenic differentiation of HEY and MDA-MB-231 PGCCs with daughter cells. Knockdown of P53 protein expression in wild-type $p 53 \mathrm{HEY}$ and mutant $p 53 \mathrm{MDA}-\mathrm{MB}-231$ cells showed that, in HEY control cells, PPARy phosphorylation is reduced and the degree of differentiation is higher, while in MDA-MB-231 PGCCs with daughter cells, PPARY phosphorylation is increased and the degree of differentiation is lower. Wild-type $p 53$ negatively regulates the adipogenic differentiation of PGCCs with daughter cells, whereas mutant $p 53$ promotes their adipogenic differentiation.

P300 is an HAT transcriptional coactivator that is critical for a multitude of cellular processes [37]. A485 is a potent, selective, and drug-like catalytic inhibitor of P300 and CBP. Lasko et al. confirmed that A485 competes with acetyl-CoA to inhibit the acetyltransferase activity of p300 [18]. Silencing P53 or p300 disrupted the P53-P300 complex and its subsequent binding to the P53 minimal promoter [38]. P300P53 regulates the acetylation level of PPARY, as confirmed by our experiments. In HEY control and PGCCs with daughter cells, P53 is regulated by P300 and undergoes ubiquitination/degradation; after adipogenic differentiation, the expression of P300 is upregulated to increase the acetylation level of PPARY. In MDAMB-2331 control and PGCCs with daughter cells, PPARY is regulated by P300 and undergoes acetylation; after adipogenic differentiation, the level of P53 acetylation is significantly increased, and the level of PPARY acetylation also increases. After adding the P300 inhibitor A485 in HEY cells, the level of P53 ubiquitination decreased, the level of P53 acetylation increased, the level of PPARy acetylation increased, and the level of FABP4 expression decreased. In MDA-MB-231 cells, the level of P53 acetylation significantly decreased, the level of PPARY acetylation decreased, and the level of FABP4 expression increased. We speculate that PPARy acetylation is positively modulated by mutation type $p 53(p 53+/-)$ in MDA-MB-231 cells, forming a P300-P53-ace-PPARy positive feedback loop. P300 negatively regulates wild-type $p 53$, and wild-type $p 53$ negatively regulates PPARY acetylation. However, the precise mechanism underlying P53 and P300 interaction requires further investigation, and the function of PPARy acetylation in the adipogenic differentiation of PGCCs with daughter cells remains to be explored.

\section{Conclusion}

FABP4 attenuates PPARy and adipogenesis in cancer cells. Our study confirms a causative link between FABP4 and PPARY and may explain some differences between the adipocyte subtypes comprising these two kinds of $p 53$ genotypes. For instance, $\mathrm{HEY}$ cells proliferate and differentiate into mature adipocytes less readily than do MDA-MB-231 cells. Thereafter, the success of inducing adipogenesis is likely due to the loss-of-function of wild-type $p 53$ and the acquisition of mutated $p 53$. FABP4 is induced by PPARy, the master regulator of adipogenesis, yet these two regulators exert opposite effects on various metabolic parameters, such as insulin resistance and inflammation [39]. Previous studies have found that PPARY activity is elevated in FABP4-null macrophages. FABP4 was reported to physically interact with PPARY 
[40], and it is likely that such a physical interaction triggers the ubiquitination and subsequent proteasomal degradation of PPARY [41]. Our findings show that FABP4 expression is not just an outcome of adipogenesis; FABP4 negatively regulates PPARY and preadipocyte differentiation. Here, we demonstrate a previously unrecognized negative feedback loop, whereby FABP4 consequently inhibits PPARy-related functions. Future studies are needed to investigate possible mechanisms that explain the opposite effects between PPARY and FABP4 in the adipogenic differentiation of PGCCs. In future studies, we will focus on searching for upstream regulators as well as downstream targets of PPARY in the adipogenic differentiation of PGCCs with daughter cells.

\section{Declarations}

\section{Acknowledgements}

We would like to thank Editage (www.editage.cn) for English language editing.

\section{Authors' contributions}

SZ designed the study and interpreted data; contributed to manuscript writing; and approved the manuscript before submission. KZ, QZ and ZL collected and analyzed data and approved the manuscript before submission. $\mathrm{HZ}$ and $\mathrm{FF}$ collected, analyzed, and interpreted data, and approved the manuscript before submission. JF and MZ collected data, gave constructive comments on the manuscript, and approved the manuscript before submission.

\section{Funding}

This work was supported in part by grants from the National Natural Science Foundation of China (81672426).

\section{Availability of data and materials}

The authors declare that all data supporting the findings of this study are available within the article and its additional files or contact the corresponding author upon reasonable request.

\section{Ethics approval and consent to participate}

The use of human tissue samples was approved by the Hospital Review Board and the confidentiality of patient information was maintained.

\section{Consent for publication}

All authors have agreed to publish this manuscript.

\section{Competing interests}

The authors declare that they have no competing interests. 


\section{Authors' information}

${ }^{1}$ School of Medicine, Nankai University, Tianjin, 300071, P.R. China

${ }^{2}$ Department of Pathology, Tianjin Union Medical Center, Nankai University, Tianjin, 300121, P.R. China

${ }^{3}$ Graduate School, Tianjin University of Traditional Chinese Medicine, Tianjin, P.R. China

${ }^{4}$ Tianjin Medical University, Tianjin, 300070, P.R. China

\section{References}

1. Contador D, Ezquer F, Espinosa M, Arango-Rodriguez M, Puebla C, Sobrevia L, Conget P. Dexamethasone and rosiglitazone are sufficient and necessary for producing functional adipocytes from mesenchymal stem cells. Experimental biology medicine. 2015;240(9):1235-46.

2. Masuda M, Yamamoto H, Takei Y, Nakahashi O, Adachi Y, Ohnishi K, Ohminami H, YamanakaOkumura $\mathrm{H}$, Sakaue $\mathrm{H}$, Miyazaki $\mathrm{M}$, et al: All-trans retinoic acid reduces the transcriptional regulation of intestinal sodium-dependent phosphate co-transporter gene (Npt2b). The Biochemical journal 2020, 477(4):817-831.

3. Nardella F, Halby L, Hammam E, Erdmann D, Cadet-Daniel V, Peronet R, Menard D, Witkowski B, Mecheri S, Scherf A, et al. DNA Methylation Bisubstrate Inhibitors Are Fast-Acting Drugs Active against Artemisinin-Resistant Plasmodium falciparum Parasites. ACS central science. 2020;6(1):1621.

4. Matheson J, Le Foll B. Therapeutic Potential of Peroxisome Proliferator-Activated Receptor (PPAR) Agonists in Substance Use Disorders: A Synthesis of Preclinical and Human Evidence. Cells 2020, $9(5)$.

5. Lefere S, Puengel T, Hundertmark J, Penners C, Frank AK, Guillot A, de Muynck K, Heymann F, Adarbes V, Defrene E, et al. Differential effects of selective- and pan-PPAR agonists on experimental steatohepatitis and hepatic macrophages. Journal of hepatology. 2020;73(4):757-70.

6. Pertzov B, Eliakim-Raz N, Atamna H, Trestioreanu AZ, Yahav D, Leibovici L. HydroxymethylglutarylCoA reductase inhibitors (statins) for the treatment of sepsis in adults-Authors' reply. Clinical microbiology infection: the official publication of the European Society of Clinical Microbiology Infectious Diseases. 2019;25(12):1572-3.

7. Kim YJ, Yu DB, Kim M, Choi YL. Adipogenesis induces growth inhibition of dedifferentiated liposarcoma. Cancer Sci. 2019;110(8):2676-83.

8. Fei F, Zhang M, Li B, Zhao L, Wang H, Liu L, Li Y, Ding P, Gu Y, Zhang X, et al. Formation of Polyploid Giant Cancer Cells Involves in the Prognostic Value of Neoadjuvant Chemoradiation in Locally Advanced Rectal Cancer. J Oncol. 2019;2019:2316436.

9. Fei F, Liu K, Li C, Du J, Wei Z, Li B, Li Y, Zhang Y, Zhang S. Molecular Mechanisms by Which S100A4 Regulates the Migration and Invasion of PGCCs With Their Daughter Cells in Human Colorectal 
Cancer. Front Oncol. 2020;10:182.

10. Zhang S, Mercado-Uribe I, Xing Z, Sun B, Kuang J, Liu J. Generation of cancer stem-like cells through the formation of polyploid giant cancer cells. Oncogene. 2014;33(1):116-28.

11. Zhang Z, Zhou Y, Qian H, Shao G, Lu X, Chen Q, Sun X, Chen D, Yin R, Zhu H, et al. Stemness and inducing differentiation of small cell lung cancer NCl-H446 cells. Cell Death Dis. 2013;4:e633.

12. Zeniou M, Nguekeu-Zebaze L, Dantzer F. Therapeutic considerations of PARP in stem cell biology: Relevance in cancer and beyond. Biochem Pharmacol. 2019;167:107-15.

13. Dobson ME, Diallo-Krou E, Grachtchouk V, Yu J, Colby LA, Wilkinson JE, Giordano TJ, Koenig RJ. Pioglitazone induces a proadipogenic antitumor response in mice with PAX8-PPARgamma fusion protein thyroid carcinoma. Endocrinology. 2011;152(11):4455-65.

14. Ishay-Ronen D, Diepenbruck M, Kalathur RKR, Sugiyama N, Tiede S, Ivanek R, Bantug G, Morini MF, Wang J, Hess C, et al. Gain Fat-Lose Metastasis: Converting Invasive Breast Cancer Cells into Adipocytes Inhibits Cancer Metastasis. Cancer Cell. 2019;35(1):17-32.e16.

15. Tang QQ, Lane MD. Adipogenesis: from stem cell to adipocyte. Annu Rev Biochem. 2012;81:715-36.

16. Hallenborg P, Feddersen S, Madsen L, Kristiansen K. The tumor suppressors pRB and p53 as regulators of adipocyte differentiation and function. Expert Opin Ther Targets. 2009;13(2):235-46.

17. Liu K, Zheng M, Zhao Q, Zhang K, Li Z, Fu F, Zhang H, Du J, Li Y, Zhang S. Different p53 genotypes regulating different phosphorylation sites and subcellular location of CDC25C associated with the formation of polyploid giant cancer cells. J Exp Clin Cancer Res. 2020;39(1):83.

18. Lasko LM, Jakob CG, Edalji RP, Qiu W, Montgomery D, Digiammarino EL, Hansen TM, Risi RM, Frey R, Manaves V, et al. Discovery of a selective catalytic p300/CBP inhibitor that targets lineage-specific tumours. Nature. 2017;550(7674):128-32.

19. Burgermeister E, Chuderland D, Hanoch T, Meyer M, Liscovitch M, Seger R. Interaction with MEK causes nuclear export and downregulation of peroxisome proliferator-activated receptor gamma. Mol Cell Biol. 2007;27(3):803-17.

20. Ji S, Park SY, Roth J, Kim HS, Cho JW. O-GlcNAc modification of PPARgamma reduces its transcriptional activity. Biochem Biophys Res Commun. 2012;417(4):1158-63.

21. Fajas L, Egler V, Reiter R, Hansen J, Kristiansen K, Debril MB, Miard S, Auwerx J. The retinoblastomahistone deacetylase 3 complex inhibits PPARgamma and adipocyte differentiation. Dev Cell. 2002;3(6):903-10.

22. Tian L, Wang C, Hagen FK, Gormley M, Addya S, Soccio R, Casimiro MC, Zhou J, Powell MJ, Xu P, et al. Acetylation-defective mutant of Ppargamma is associated with decreased lipid synthesis in breast cancer cells. Oncotarget. 2014;5(17):7303-15.

23. Dornan D, Shimizu H, Perkins ND, Hupp TR. DNA-dependent acetylation of p53 by the transcription coactivator p300. J Biol Chem. 2003;278(15):13431-41.

24. Chen Z, Liu X, Li F, Li C, Marquez-Lago T, Leier A, Akutsu T, Webb GI, Xu D, Smith Al, et al. Large-scale comparative assessment of computational predictors for lysine post-translational modification sites. 
Brief Bioinform. 2019;20(6):2267-90.

25. Zhang K, Yang X, Zhao Q, Li Z, Fu F, Zhang H, Zheng M, Zhang S. Molecular Mechanism of Stem Cell Differentiation into Adipocytes and Adipocyte Differentiation of Malignant Tumor. Stem Cells Int. 2020;2020:8892300.

26. Sarjeant K, Stephens JM. Adipogenesis. Cold Spring Harb Perspect Biol. 2012;4(9):a008417.

27. Fajas L. Adipogenesis: a cross-talk between cell proliferation and cell differentiation. Ann Med. 2003;35(2):79-85.

28. Fu M, Wang C, Zhang X, Pestell RG. Acetylation of nuclear receptors in cellular growth and apoptosis. Biochem Pharmacol. 2004;68(6):1199-208.

29. Choi HR, Kim WK, Kim EY, Han BS, Min JK, Chi SW, Park SG, Bae KH, Lee SC. Dual-specificity phosphatase 10 controls brown adipocyte differentiation by modulating the phosphorylation of p38 mitogen-activated protein kinase. PLoS One. 2013;8(8):e72340.

30. Quelle FW, Sigmund CD. PPARgamma: no SirT, no service. Circ Res. 2013;112(3):411-4.

31. Lehrke M, Lazar MA. The many faces of PPARgamma. Cell. 2005;123(6):993-9.

32. Michalik L, Desvergne B, Wahli W. Peroxisome-proliferator-activated receptors and cancers: complex stories. Nat Rev Cancer. 2004;4(1):61-70.

33. Szanto M, Bai P. The role of ADP-ribose metabolism in metabolic regulation, adipose tissue differentiation, and metabolism. Genes Dev. 2020;34(5-6):321-40.

34. Helenius K, Yang Y, Alasaari J, Makela TP. Mat1 inhibits peroxisome proliferator-activated receptor gamma-mediated adipocyte differentiation. Mol Cell Biol. 2009;29(2):315-23.

35. Gao Y, Koppen A, Rakhshandehroo M, Tasdelen I, van de Graaf SF, van Loosdregt J, van Beekum O, Hamers N, van Leenen D, Berkers CR, et al. Early adipogenesis is regulated through USP7-mediated deubiquitination of the histone acetyltransferase TIP60. Nat Commun. 2013;4:2656.

36. King TC, Estalilla OC, Safran H. Role of p53 and p16 gene alterations in determining response to concurrent paclitaxel and radiation in solid tumor. Semin Radiat Oncol. 1999;9(2 Suppl 1):4-11.

37. Thompson PR, Wang D, Wang L, Fulco M, Pediconi N, Zhang D, An W, Ge Q, Roeder RG, Wong J, et al. Regulation of the p300 HAT domain via a novel activation loop. Nat Struct Mol Biol. 2004;11(4):30815.

38. Clark S, Myers JB, King A, Fiala R, Novacek J, Pearce G, Heierhorst J, Reichow SL, Barbar EJ. Multivalency regulates activity in an intrinsically disordered transcription factor. Elife 2018, 7.

39. Tontonoz P, Graves RA, Budavari Al, Erdjument-Bromage H, Lui M, Hu E, Tempst P, Spiegelman BM. Adipocyte-specific transcription factor ARF6 is a heterodimeric complex of two nuclear hormone receptors, PPAR gamma and RXR alpha. Nucleic Acids Res. 1994;22(25):5628-34.

40. Adida A, Spener F. Adipocyte-type fatty acid-binding protein as inter-compartmental shuttle for peroxisome proliferator activated receptor gamma agonists in cultured cell. Biochim Biophys Acta. 2006;1761(2):172-81. 
41. Garin-Shkolnik T, Rudich A, Hotamisligil GS, Rubinstein M. FABP4 attenuates PPARgamma and adipogenesis and is inversely correlated with PPARgamma in adipose tissues. Diabetes. 2014;63(3):900-11.

\section{Figures}
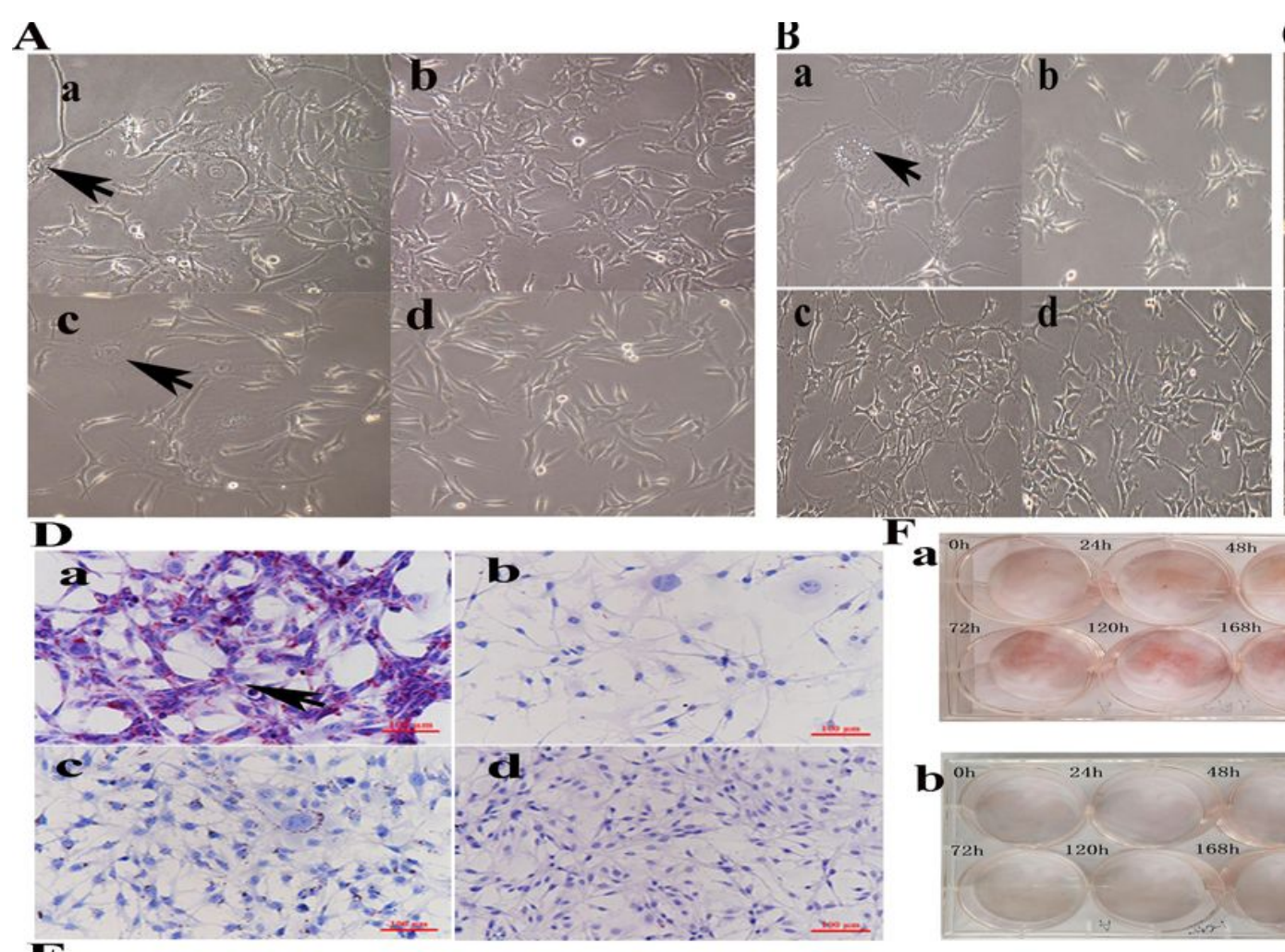

C

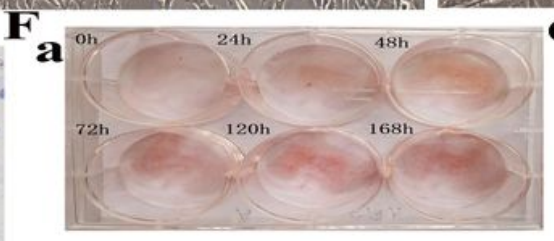

$\mathbf{E}$
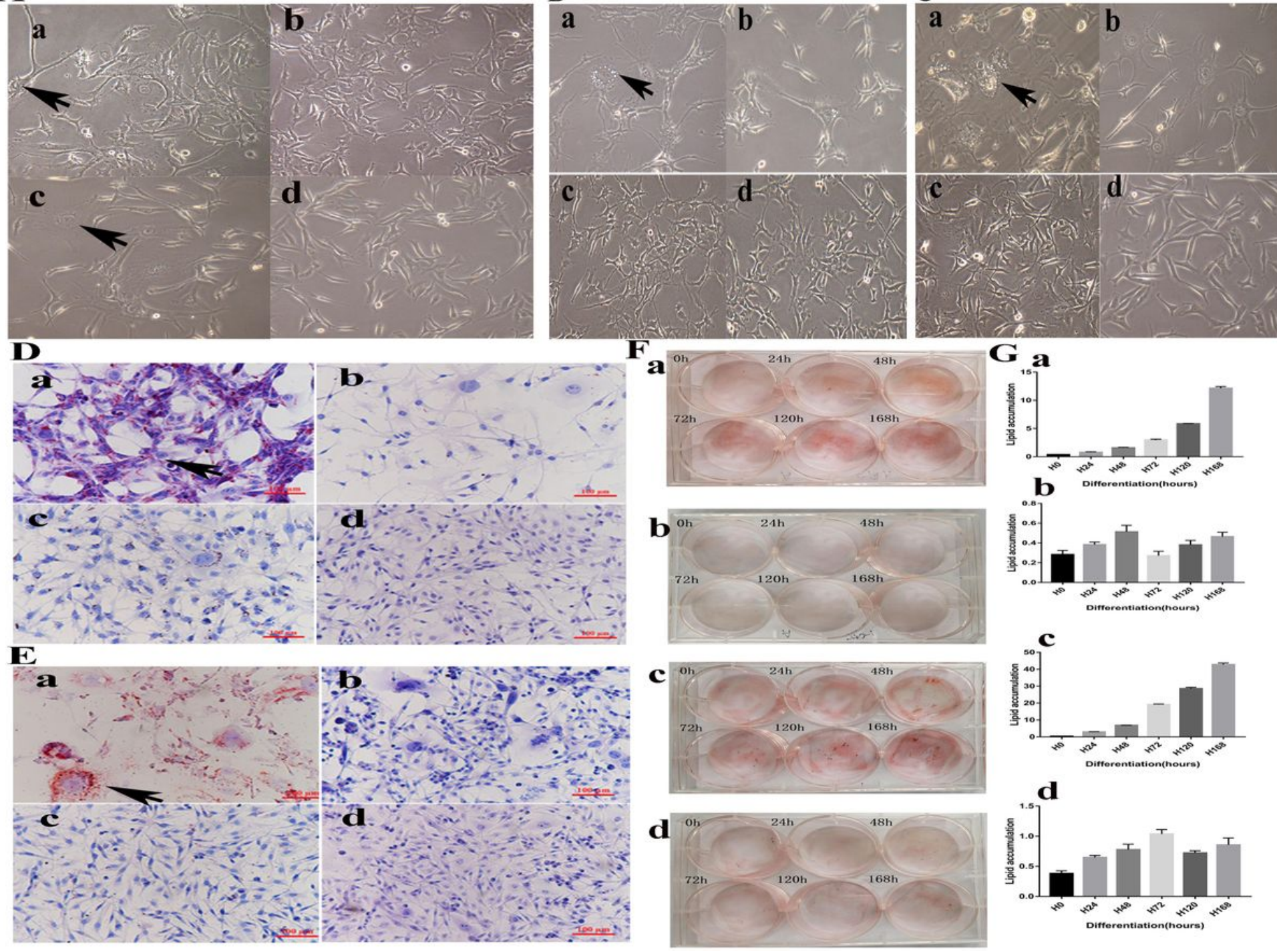

\section{Figure 1}

Cancer cells differentiated in adipocyte differentiation media (A) HEY and MDA-MB-231 control and polyploid giant cancer cells (PGCCs) (a) HEY PGCCs with daughter cells induced by $450 \mu \mathrm{M} \mathrm{CoCl} 2$ treatment for 48 h. (b) HEY control cells. (c) MDA-MB-231 PGCCs with daughter cells induced by $450 \mu \mathrm{M}$ $\mathrm{CoCl} 2$ treatment for $48 \mathrm{~h}$. (d) MDA-MB-231 control cells. (B) HEY cell morphology with and without differentiation (100x). (a) HEY PGCCs with daughter cells at $168 \mathrm{~h}$ in adipogenic differentiation medium. (b) HEY PGCCs with daughter cells without differentiation. (c) HEY control cells at $168 \mathrm{~h}$ in adipogenic differentiation medium. (d) HEY control cells without differentiation. (C) MDA-MB-231 cell morphology with and without differentiation (100x). (a) MDA-MB-231 PGCCs with daughter cells at $168 \mathrm{~h}$ in 
adipogenic differentiation medium. (b) MDA-MB-231 PGCCs with daughter cells without differentiation. (c) MDA-MB-231 control cells at $168 \mathrm{~h}$ in adipogenic differentiation medium. (d) MDA-MB-231 control cells without differentiation. (D) Oil Red O (ORO) staining of HEY cells with and without differentiation (100x). (a) HEY PGCCs with daughter cells at $168 \mathrm{~h}$ in adipogenic differentiation medium (b) HEY PGCCs with daughter cells without differentiation. (c) HEY control cells at $168 \mathrm{~h}$ in adipogenic differentiation medium. (d) HEY control cells without differentiation. (E) ORO staining of MDA-MB-231 cells with and without differentiation (100x). (a) MDA-MB-231 PGCCs with daughter cells at $168 \mathrm{~h}$ in adipogenic differentiation medium (b) MDA-MB-231 PGCCs with daughter cells without differentiation. (c) MDA-MB231 control cells at $168 \mathrm{~h}$ in adipogenic differentiation medium. (d) MDA-MB-231 control cells without differentiation. (F) Adipogenic differentiation at 0, 24, 28, 72, 120, and $168 \mathrm{~h}$. Intracellular lipid droplets in differentiated adipocytes were stained with ORO for image analysis. (a) HEY PGCCs with daughter cells. (b) HEY control cells. (c) MDA-MB-231 PGCCs with daughter cells. (d) MDA-MB-231 control cells. (G) ORO-stained lipid droplets were extracted for quantification of lipid accumulation. (a) HEY PGCCs with daughter cells. (b) HEY control cells. (c) MDA-MB-231 PGCCs with daughter cells. (b) MDA-MB-231 control cells.
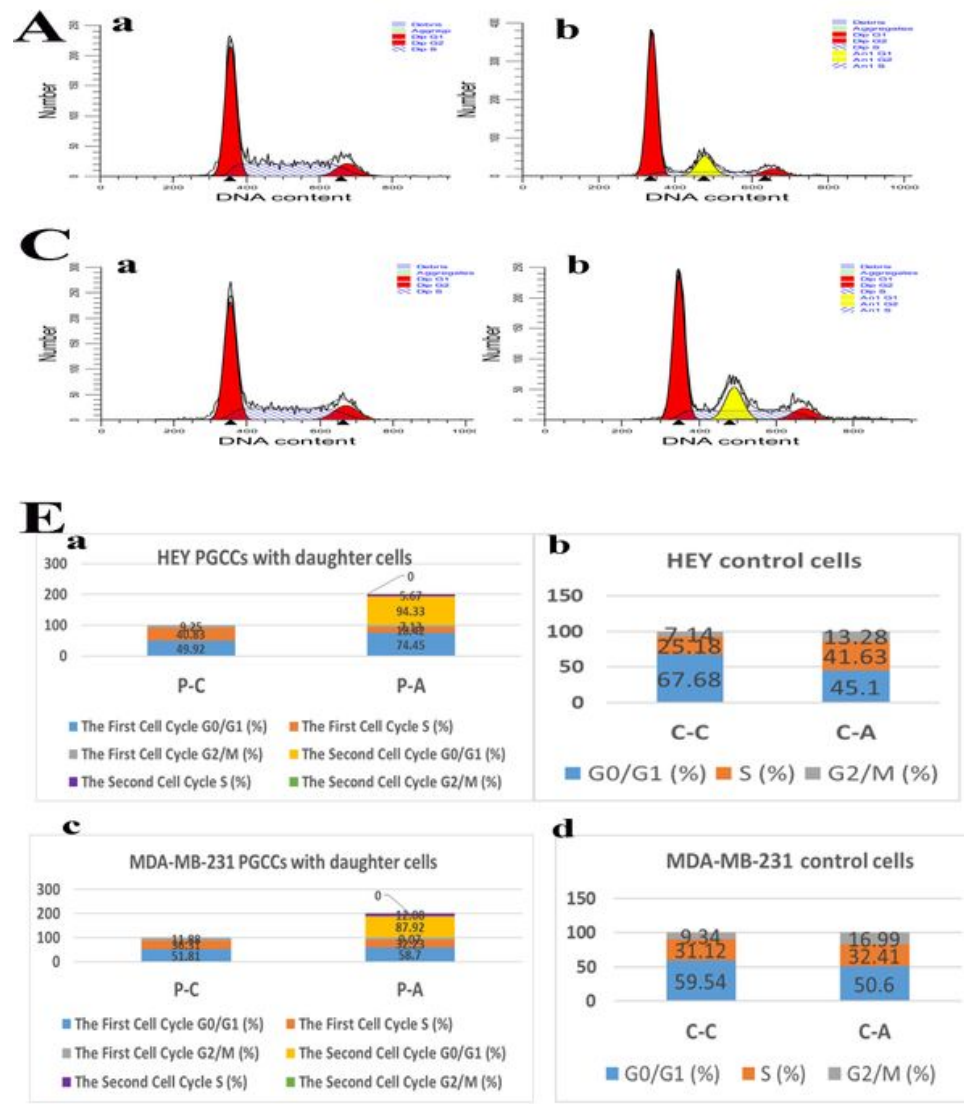

$\mathbf{H}$
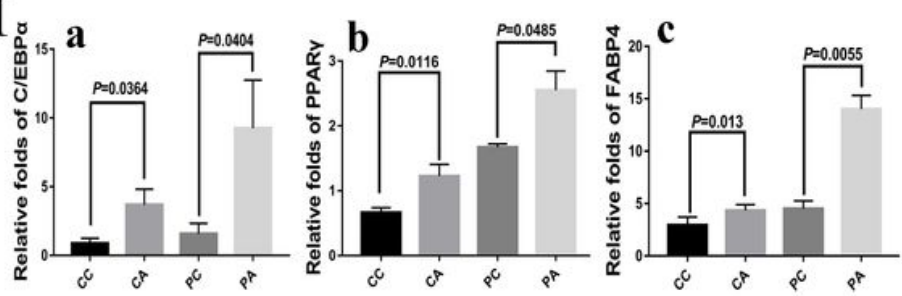
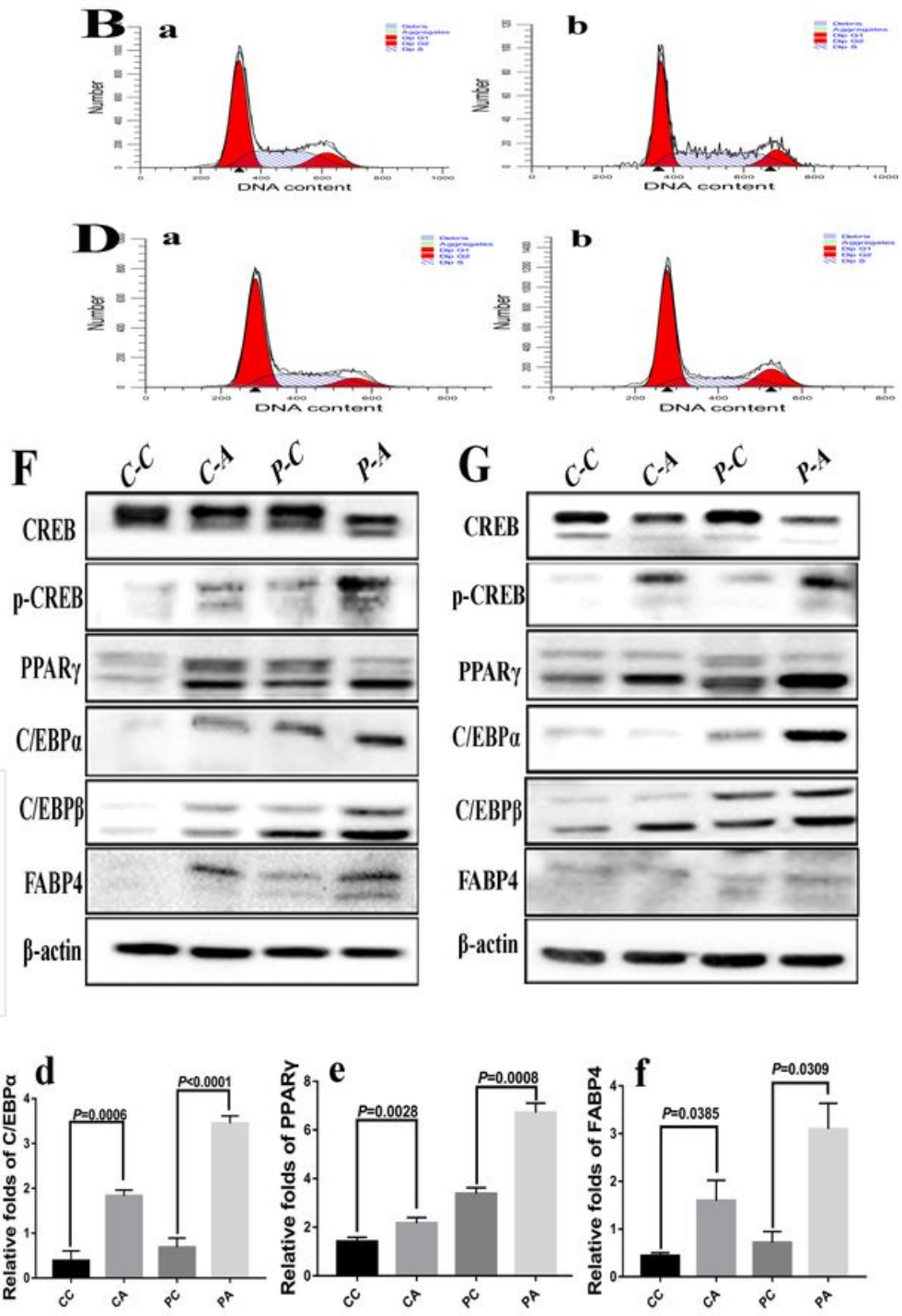

Figure 2 
Cancer cells differentiated into fully differentiated adipocytes (A) Flow cytometry analysis of the cell cycle in HEY polyploid giant cancer cells (PGCCs) with daughter cells (a) before differentiation and (b) at $168 \mathrm{~h}$ in adipogenic differentiation medium. (B) Flow cytometry analysis of the cell cycle in HEY control cells (a) before differentiation and (b) at $168 \mathrm{~h}$ in adipogenic differentiation medium. (C) Flow cytometry analysis of the cell cycle in MDA-MB231 PGCCs with daughter cells (a) before differentiation and (b) at $168 \mathrm{~h}$ in adipogenic differentiation medium. (D) Flow cytometry analysis of the cell cycle in MDA-MB-231 control cells (a) before differentiation and (b) at $168 \mathrm{~h}$ in adipogenic differentiation medium. (E) Columnar percentage plot showing the ratio of cells at the G1, S, and G2 stages of the cell cycle before and after differentiation. (F) Western blot showing the total expression of CREB, phospho-CREB(Ser133), PPARY, C/EBPa, C/EBPB, and FABP4 in HEY control and PGCCs with daughter cells before and after differentiation. $(G)$ Western blot showing the total expression of CREB, phospho-CREB(Ser133), PPARY, $\mathrm{C} / \mathrm{EBPa}, \mathrm{C} / \mathrm{EBP} \beta$, and FABP4 in MDA-MB-231 control and PGCCs with daughter cells before and after differentiation. $(\mathrm{H})$ Real-time quantitative PCR confirmation of C/EBPa, PPARY, and FABP4 expression before and after differentiation. (a) Expression levels of C/EBPa in the four groups of HEY. (b) Expression levels of PPARY in the four groups of HEY. (c) Expression levels of FABP4 in four the groups of HEY. (d) Expression levels of C/EBPa in the four groups of MDA-MB-231. (e) Expression levels of PPARY in the four groups of MDA-MB-231. (f) Expression levels of FABP4 in the four groups of MDA-MB-231. C-C: control cells; C-A: control cells with adipogenic differentiation treatment; P-C: PGCCs with daughter cells; P-A: PGCCs with daughter cells with adipogenic differentiation treatment. 

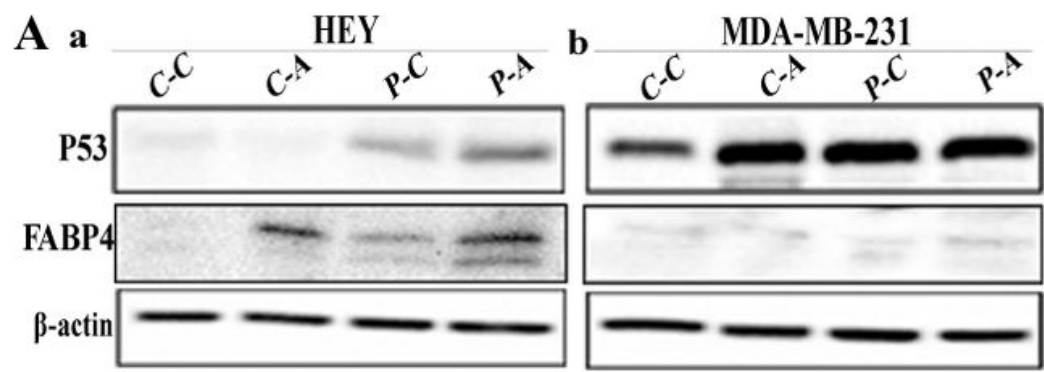

c
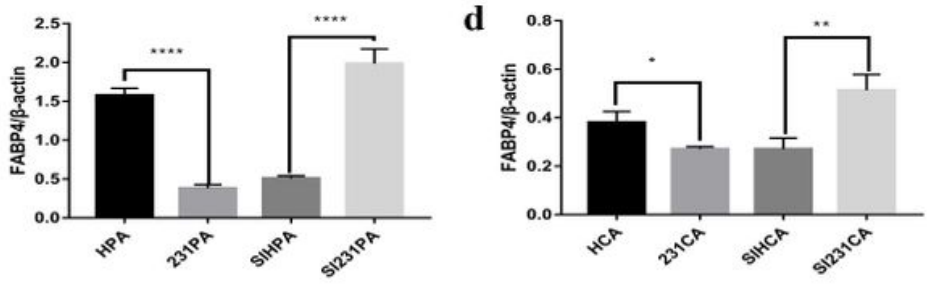

B

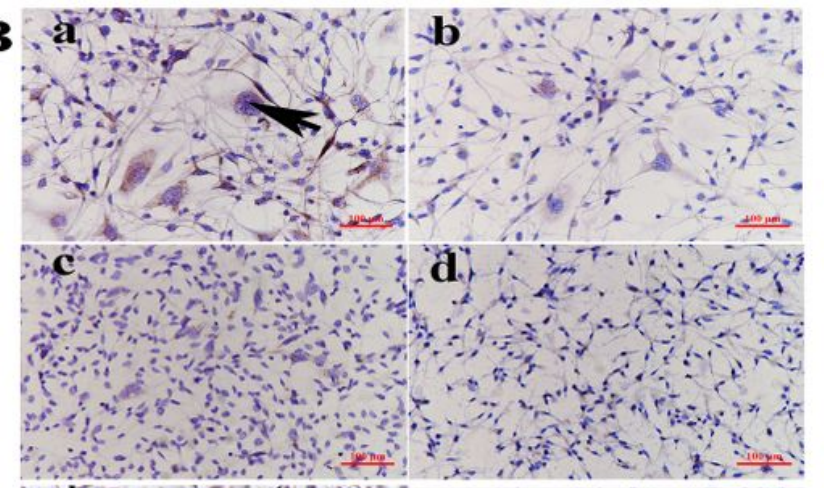

$\mathbf{C}^{\prime \prime}$

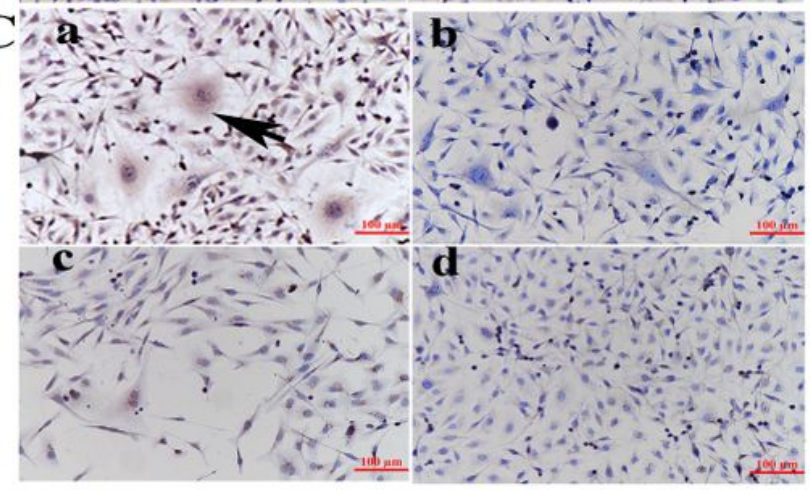

D HEY PGCCs with daughter cells $\mathbf{E}$

HEY control cells
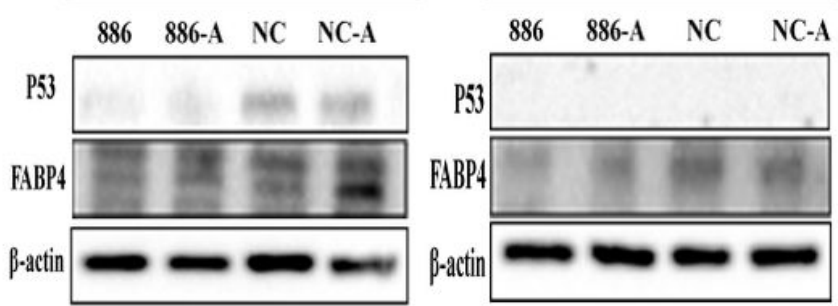

F MDA-MB-231 PGCCs with daughter cells

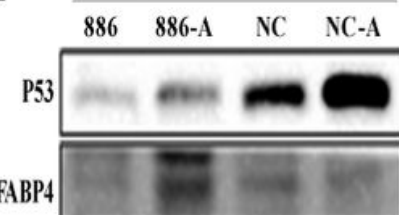

FABP4

$\beta$-actin

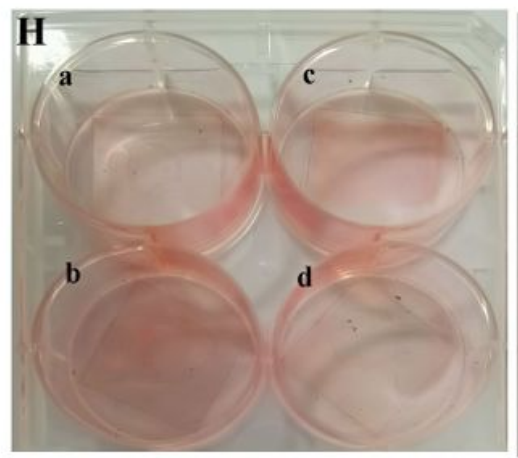

I

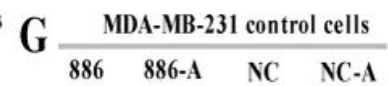

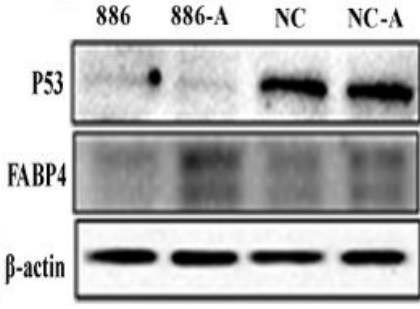

J

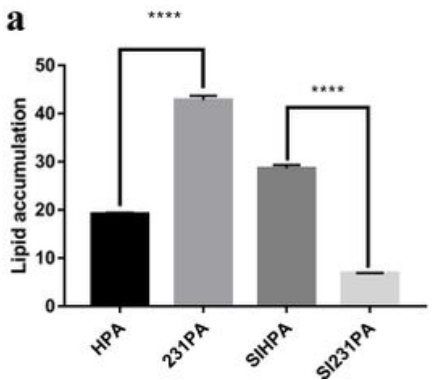

b

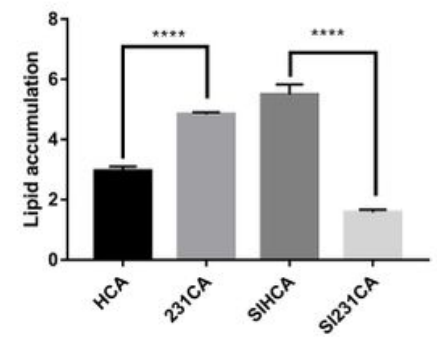

Figure 3

FABP4 expression in HEY and MDA-MB-231 cells before and after adipogenic differentiation (A) Western blot showing the total expression of p53 and FABP4 in HEY and MDA-MB-231 control and polyploid giant cancer cells (PGCCs) with daughter cells before and after differentiation. (a) P53 and FABP4 expression in HEY. (b) P53 and FABP4 expression in MDA-MB-231. (B) Immunocytochemical (ICC) staining of FABP4 in HEY cells with and without differentiation. (a) HEY PGCCs with daughter cells at $168 \mathrm{~h}$ in adipogenic differentiation medium (b) HEY PGCCs with daughter cells without differentiation. (c) HEY control cells at $168 \mathrm{~h}$ in adipogenic differentiation medium. (d) HEY control cells without differentiation. (C) ICC staining of FABP4 in MDA-MB-231 cells before and after differentiation. (a) MDA-MB-231 PGCCs with daughter cells at $168 \mathrm{~h}$ in adipogenic differentiation medium (b) MDA-MB-231 PGCCs with daughter cells without differentiation. (c) MDA-MB-231 control cells at $168 \mathrm{~h}$ in adipogenic differentiation medium. (d) MDA-MB- 
231 control cells without differentiation. (D)-(G) Western blot showing the total expression of P53 and FABP4 after siRNA-p53 transfection in HEY and MDA-MB-231 control and PGCCs with daughter cells with and without adipogenic differentiation. $(\mathrm{H})$ Adipogenic-differentiated PGCCs before and after siRNA-p53 transfection. Intracellular lipid droplets in differentiated adipocytes were stained with Oil Red O (ORO) for image analysis. (a) HEY PGCCs with daughter cells before transfection. (b) MDA-MB-231 PGCCs with daughter cells before transfection. (c) HEY PGCCs with daughter cells after transfection. (d) MDA-MB-231 PGCCs with daughter cells after transfection. (I) Adipogenic-differentiated control cells before and after siRNA-p53 transfection. Intracellular lipid droplets in differentiated adipocytes were stained with ORO for image analysis. (a) HEY control cells before transfection. (b) MDA-MB-231 control cells before transfection. (c) HEY control cells after transfection. (d) MDA-MB-231 control cells after transfection (J) ORO-stained lipid droplets were extracted for quantification of lipid accumulation. C-C: control cells; C-A: control cells with adipogenic differentiation treatment; P-C: PGCCs with daughter cells; P-A: PGCCs with daughter cells with adipogenic differentiation treatment. 886: cells after siRNA P53-886 transfection; 886A: cells with adipogenic differentiation treatment after siRNA P53-886 transfection; NC: cells after siRNA P53-negative control transfection; NC-A: cells with adipogenic differentiation treatment after siRNA P53negative control transfection. 


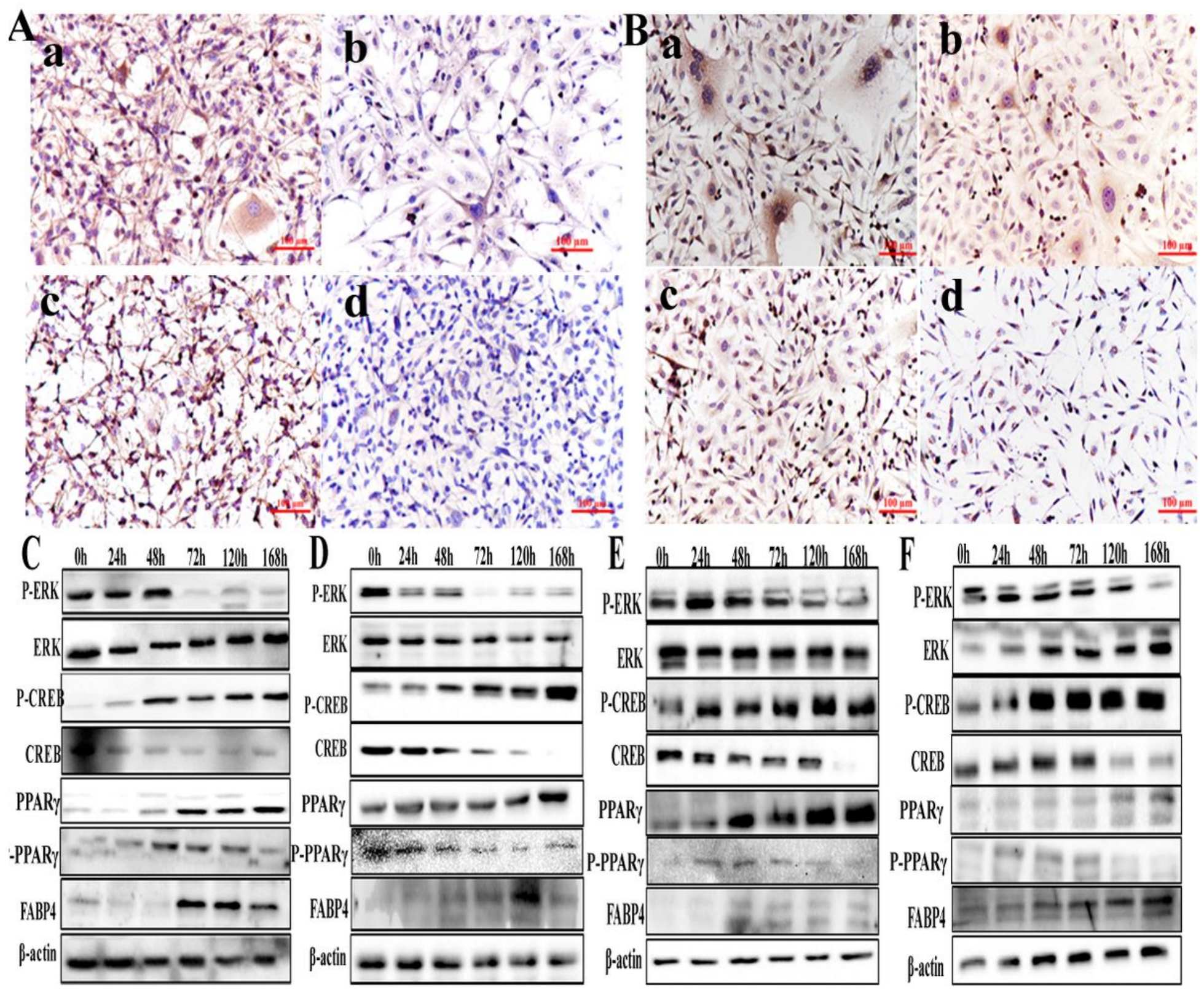

\section{Figure 4}

Time-dependent expression of ERK phosphorylation and PPARy phosphorylation in the adipogenic differentiation of HEY and MDA-MB-231 cells (A) Immunocytochemical (ICC) staining of PPARY in (a) HEY polyploid giant cancer cells (PGCCs) with daughter cells after differentiation, (b) HEY PGCCs with daughter cells before differentiation, (c) HEY control cells after differentiation, and (d) HEY control cells before differentiation. (B) ICC staining of PPARY in (a) MDA-MB-231 PGCCs with daughter cells after differentiation, (b) MDA-MB-231 PGCCs with daughter cells before differentiation, (c) MDA-MB-231 control cells after differentiation, and (d) MDA-MB-231 control cells before differentiation. (C)-(D) Western blot showing the time-dependent expression of ERK-phospho-ERK(Thr202/Tyr204)-CREB-phosphoCREB(Ser133)-PPARy-phospho-PPARY(Ser112)-FABP4 in early differentiation (168 $\mathrm{h}$ after induction) of (C) HEY PGCCs with daughter cells and (D) HEY control cells. (E)-(F) Western blot showing the time- 
dependent expression of ERK-phospho-ERK(Thr202/Tyr204) -CREB-phospho-CREB(Ser133)-PPARYphospho-PPARY(Ser112)-FABP4 in early differentiation (168 h after induction) of (E) MDA-MB-231 PGCCs with daughter cells and (F) MDA-MB-231 control cells.
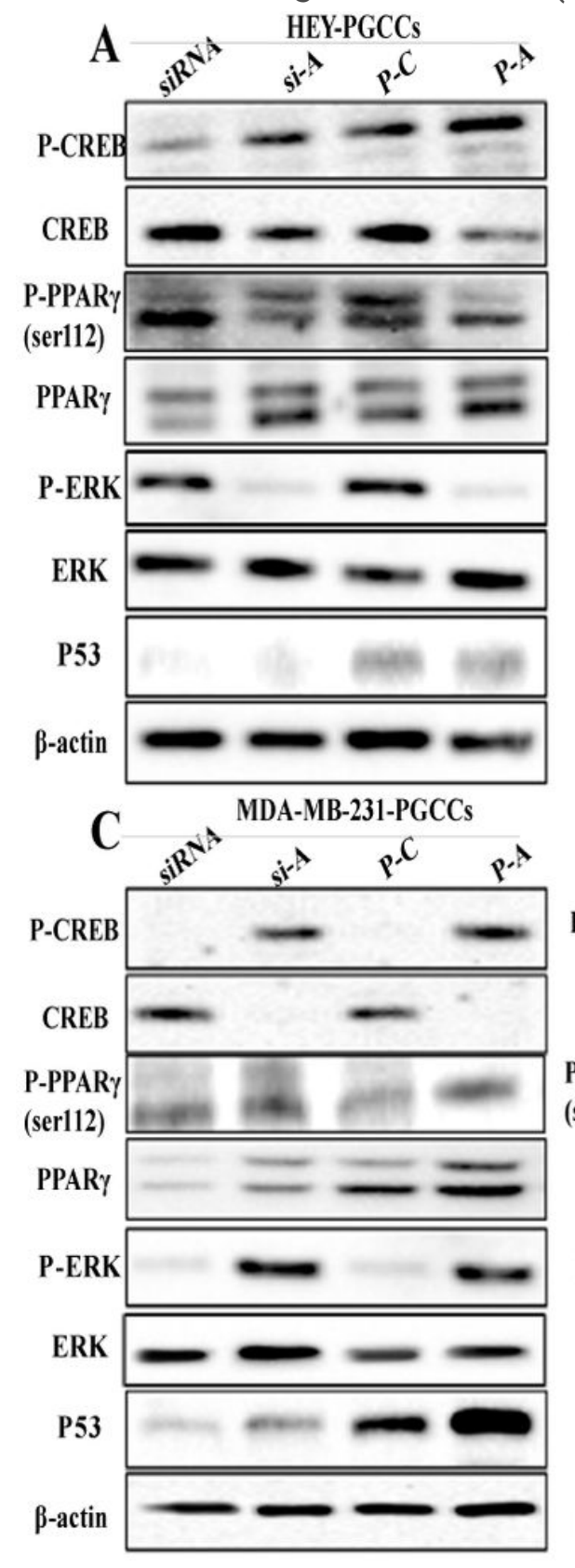

\section{HEY-CTR}
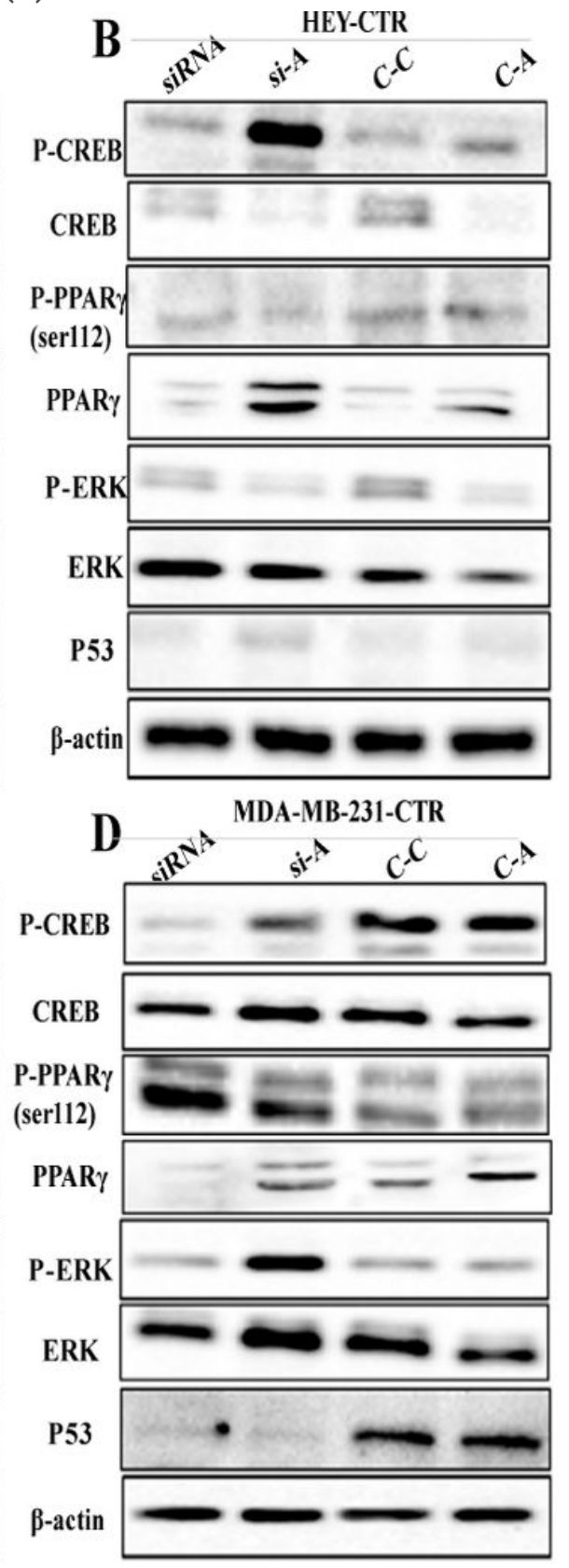
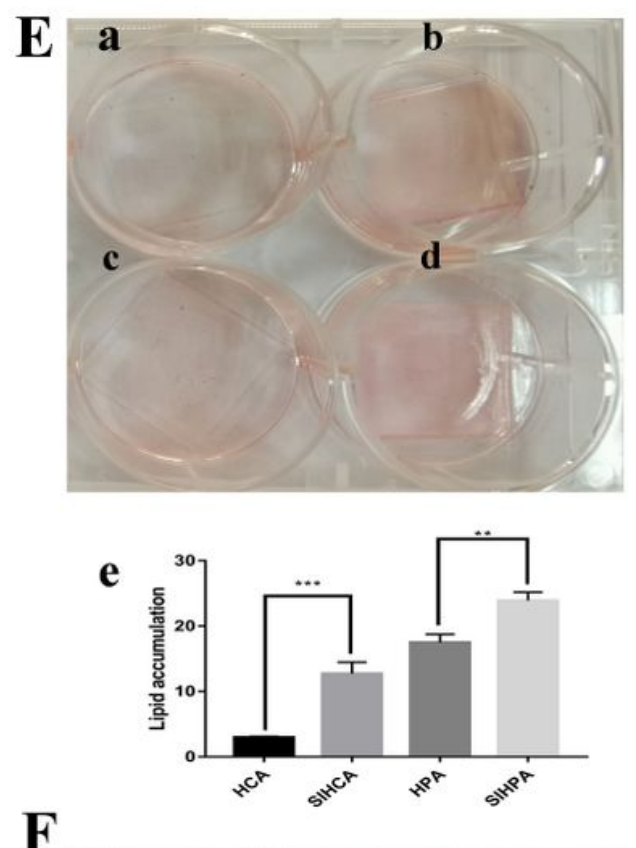

$\mathbf{F}$

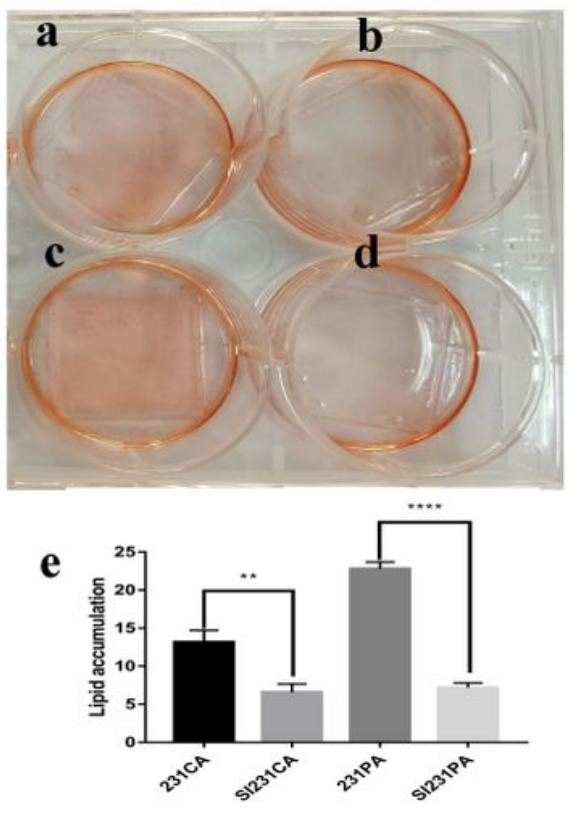

Figure 5

P53-ERK-phospho-ERK(Thr202/Tyr204)-CREB-phospho-CREB(Ser133)-PPARy-phosphoPPARY(Ser112)-FABP4 in the adipogenic differentiation of HEY and MDA-MB-231 cells before and after siRNA-p53 transfection. (A)-(D) Western blot showing the P53-ERK-phospho-ERK(Thr202/Tyr204)CREB-phospho-CREB(Ser133)-PPARY-phospho-PPARy(Ser112)-FABP4 in the adipogenic differentiation of cells before and after siRNA-p53 transfection: (A) HEY polyploid giant cancer cells (PGCCs) with daughter cells, (B) HEY control cells, (C) MDA-MB-231 PGCCs with daughter cells, and (D) MDA-MB-231 control cells. (E) HEY cells at $168 \mathrm{~h}$ in adipogenic differentiation medium before and after 
siRNA-p53 transfection. Intracellular lipid droplets in differentiated adipocytes were stained with Oil Red 0 (ORO) for image analysis: (a) HEY control cells, (b) HEY control cells after siRNA-p53 transfection, (c) HEY PGCCs with daughter cells, and (d) HEY PGCCs with daughter cells after siRNA-p53 transfection. (e) ORO-stained lipid droplets were extracted for quantification of lipid accumulation. (F) MDA-MB-231 cells at $168 \mathrm{~h}$ in adipogenic differentiation medium before and after siRNA-p53 transfection: (a) MDA-MB-231 control cells, (b) MDA-MB-231 control cells after siRNA-p53 transfection, (c) MDA-MB-231 PGCCs with daughter cells, and (d) MDA-MB-231 PGCCs with daughter cells after siRNA-p53 transfection. (e) OROstained lipid droplets were extracted for quantification of lipid accumulation. C-C: control cells; C-A: control cells with adipogenic differentiation treatment; P-C: PGCCs with daughter cells; P-A: PGCCs with daughter cells with adipogenic differentiation treatment; si-A: cells with adipogenic differentiation treatment after siRNA P53-985 transfection.

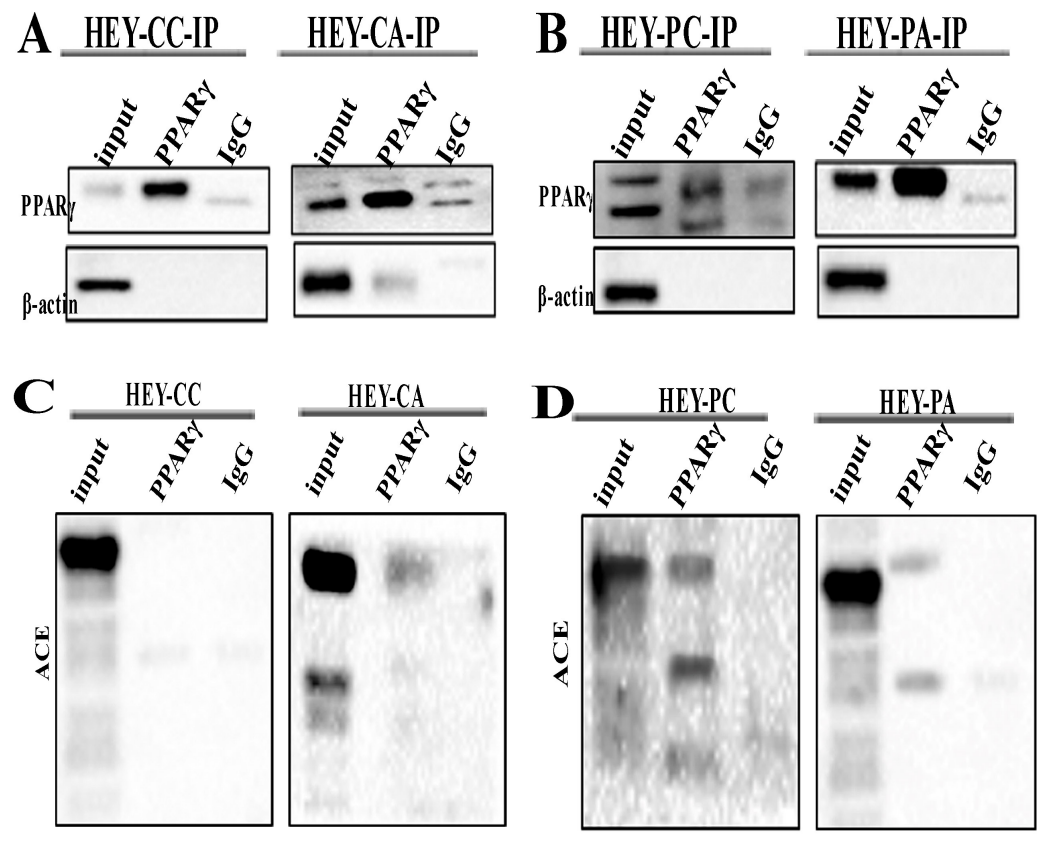

E MDA-MB-231-CC-IPMDA-MB-231-CA-IP
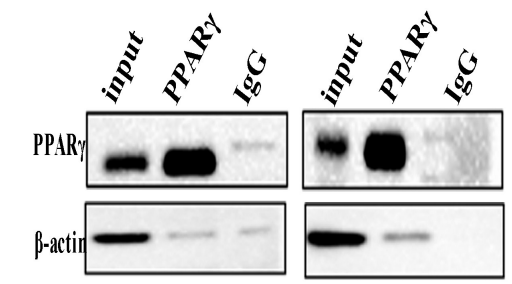

G
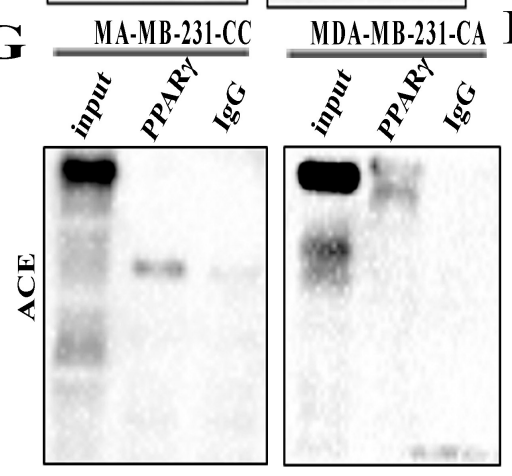

F MDA-MB-231-PC-IPMDA-MB-231-PA-IP
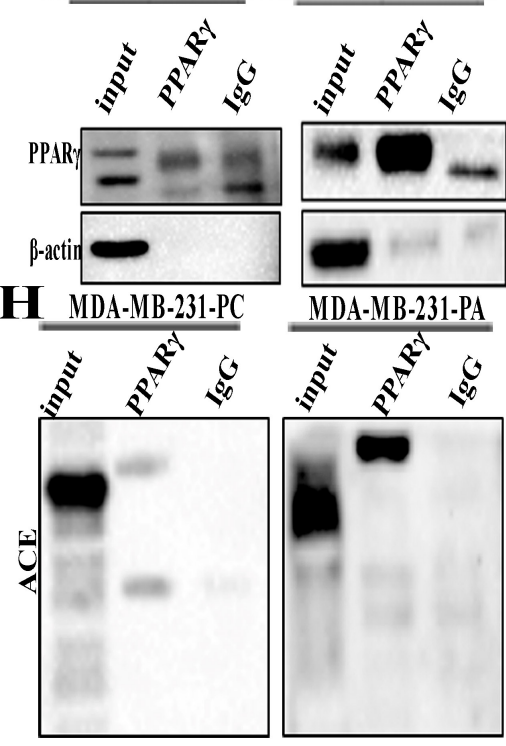
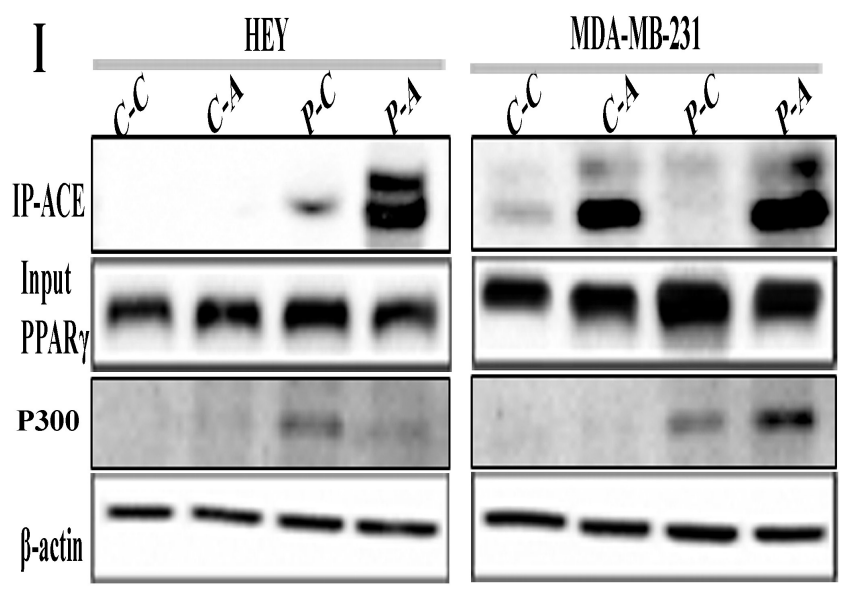

$\mathbf{J}$
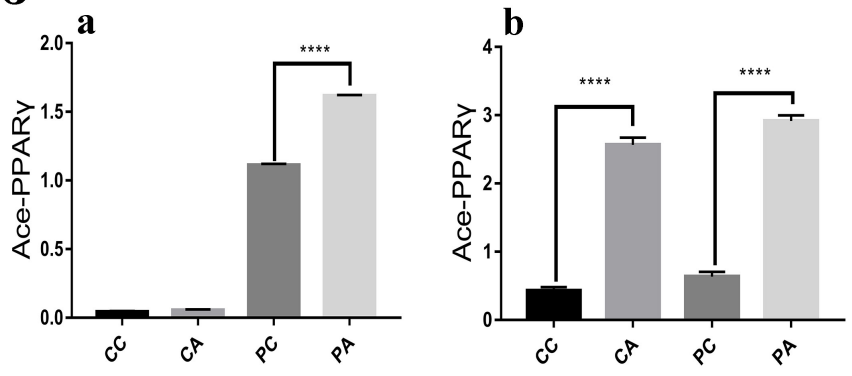

K
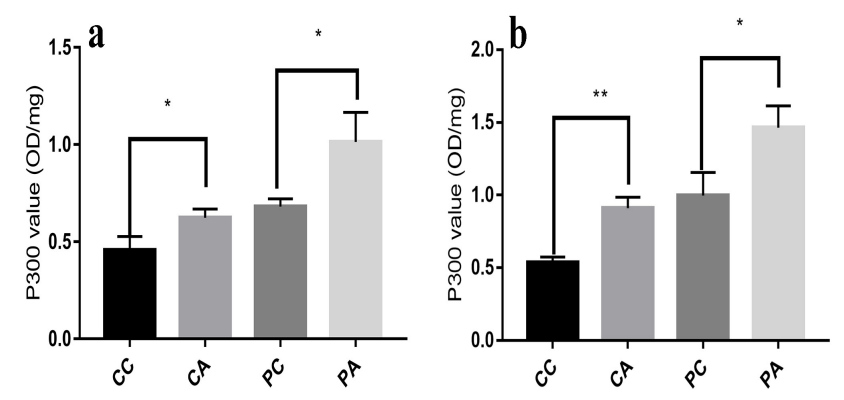

Figure 6 
Acetylation of PPARY in HEY and MDA-MB-231 cells before and after adipogenic differentiation (A)-(D) PPARY immunoprecipitation (IP) assay in total lysates of HEY control and polyploid giant cancer cells (PGCCs) with daughter cells before and after adipogenic differentiation. (A) HEY control cells immunoprecipitated with anti-PPARY. (B) HEY PGCCs immunoprecipitated with anti-PPARY. (C) HEY control cells immunoblotted with anti-ACE. (D) HEY PGCCs immunoblotted with anti-ACE. (E)-(H) PPARY IP assay in total lysates of MDA-MB-231 control and PGCCs with daughter cells before and after adipogenic differentiation treatment. (E) MDA-MB-231 control cells immunoprecipitated with anti-PPARY. (F) MDA-MB-231 PGCCs immunoprecipitated with anti-PPARy. (G) MDA-MB-231 control cells immunoblotted with anti-ACE. (H) MDA-MB-231 PGCCs immunoblotted with anti-ACE. (I) Expression of acetylated PPARY and P300 in HEY and MDA-MB-231 control and PGCCs with daughter cells before and after differentiation. (J) Histogram of ace-PPARy expression in (a) HEY and (b) MDA-MB-231 control and PGCCs with daughter cells before and after differentiation. (K) Histogram of P300 HAT activity assay in (a) HEY and (b) MDA-MB-231 control and PGCCs with daughter cells before and after differentiation. C-C, control cells; C-A, control cells with adipogenic differentiation treatment; P-C, PGCCs with daughter cells; P-A: PGCCs with daughter cells with adipogenic differentiation treatment. HAT: Histone acetyltransferase. 


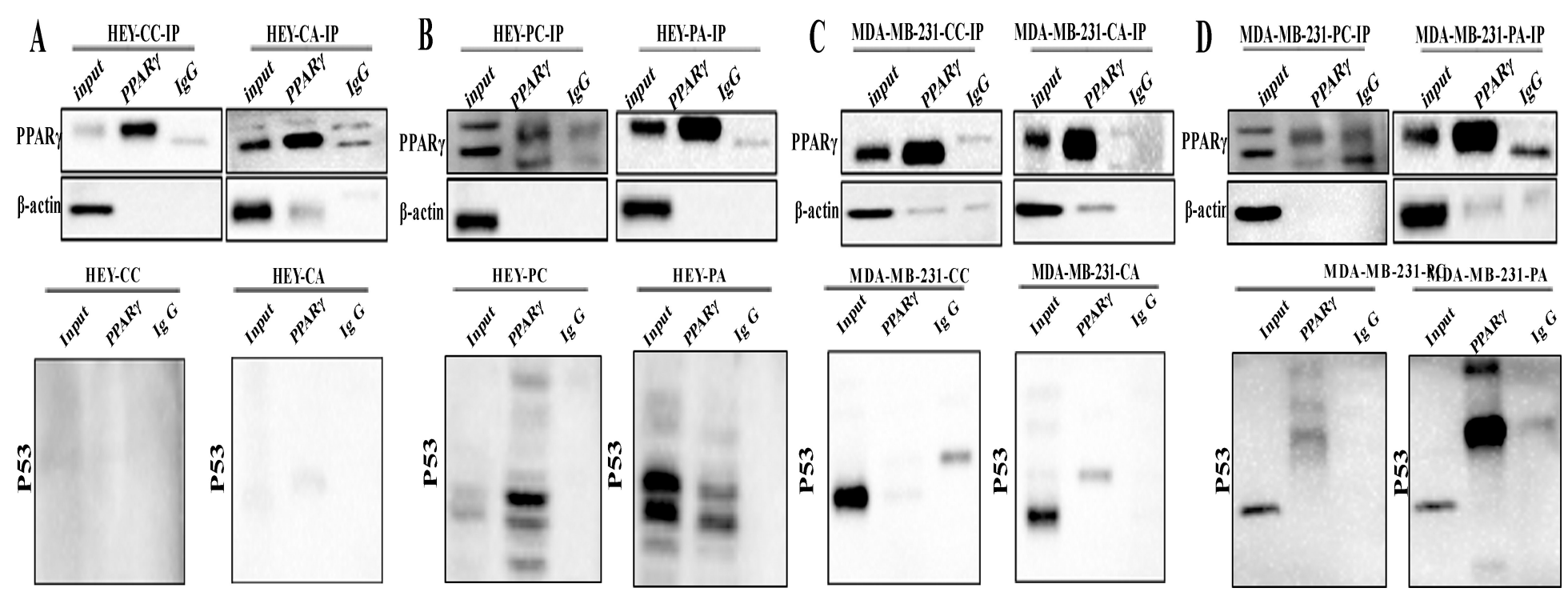

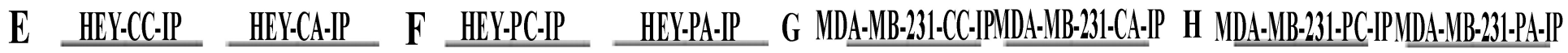

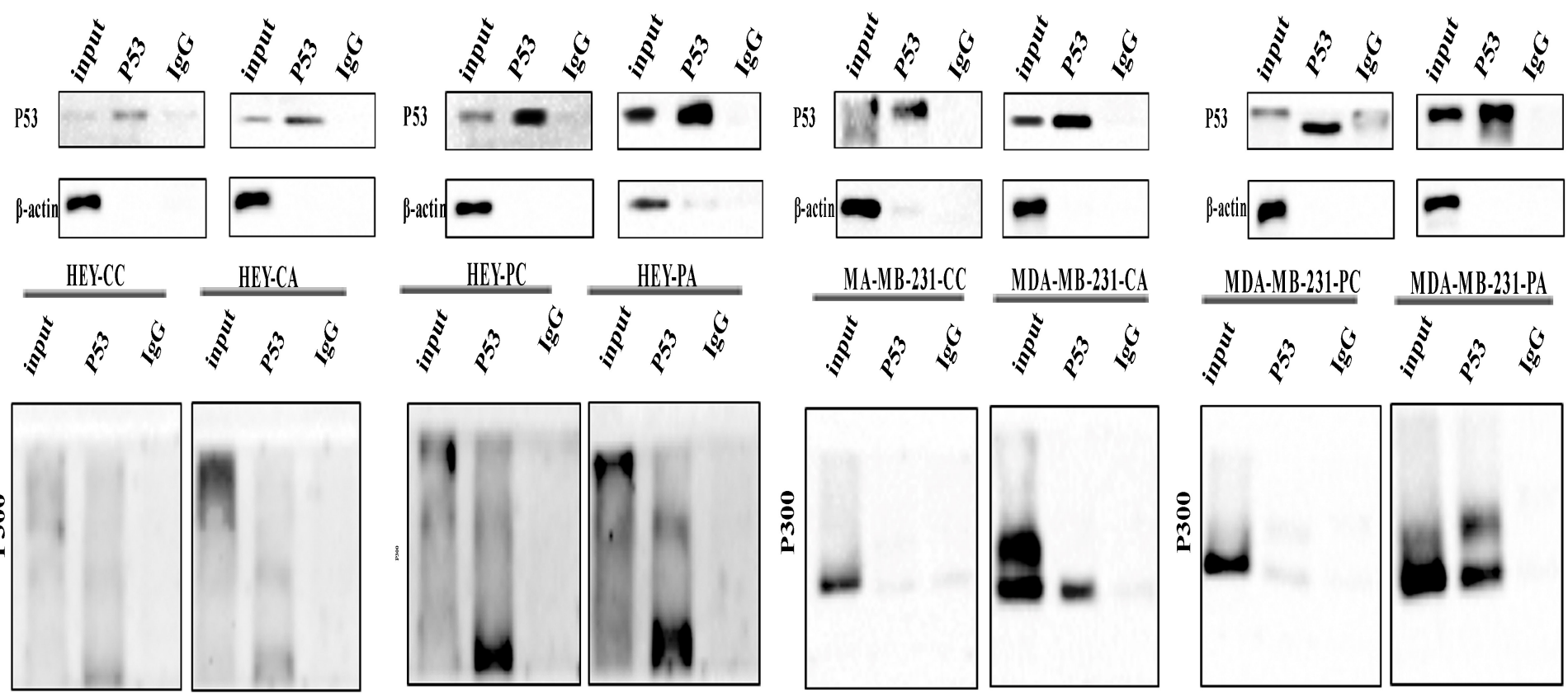

\section{Figure 7}

Co-immunoprecipitation and western blots showing the interaction among P53, P300, and PPARY in the adipogenic differentiation of HEY and MDA-MB-231 (A)-(D) Total lysates of HEY and MDA-MB-231 control and polyploid giant cancer cells (PGCCs) with daughter cells, before and after adipogenic differentiation, immunoprecipitated with anti-PPARy and immunoblotted with anti-P53. (A) HEY control cells. (B) HEY PGCCs with daughter cells. (C) MDA-MB-231 control cells. (D) MDA-MB-231 PGCCs with daughter cells. (E)-(H) Total lysates of HEY and MDA-MB-231 control and PGCCs with daughter cells, before and after adipogenic differentiation, immunoprecipitated with anti-P53 and immunoblotted with anti-P300. (E) HEY control cells. (F) HEY PGCCs with daughter cells (G) MDA-MB-231 control cells. (H) MDA-MB-231 PGCCs with daughter cells. 
A
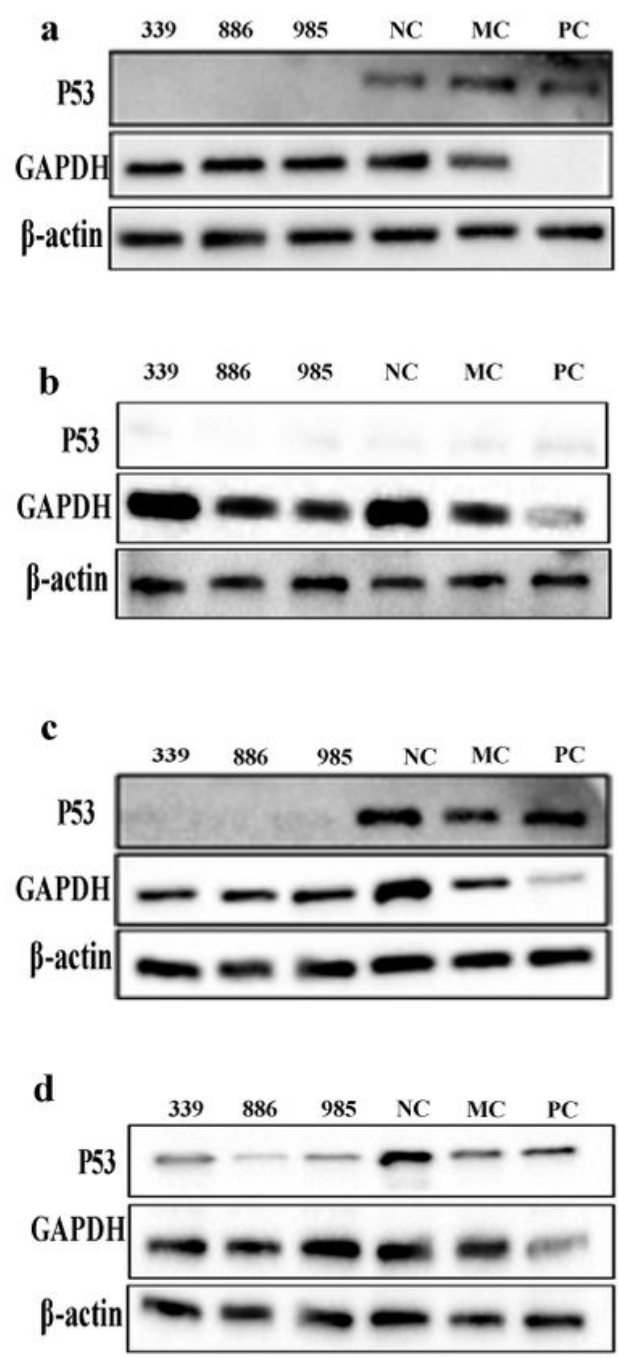

B

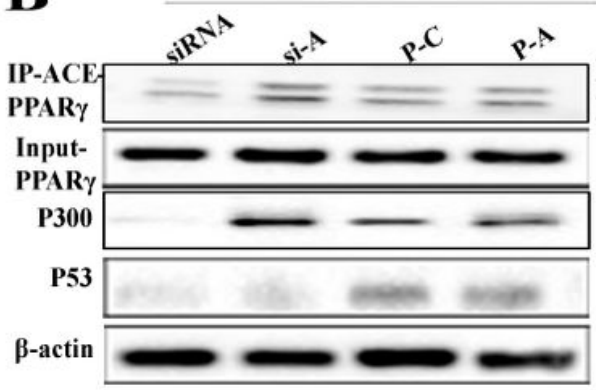

C
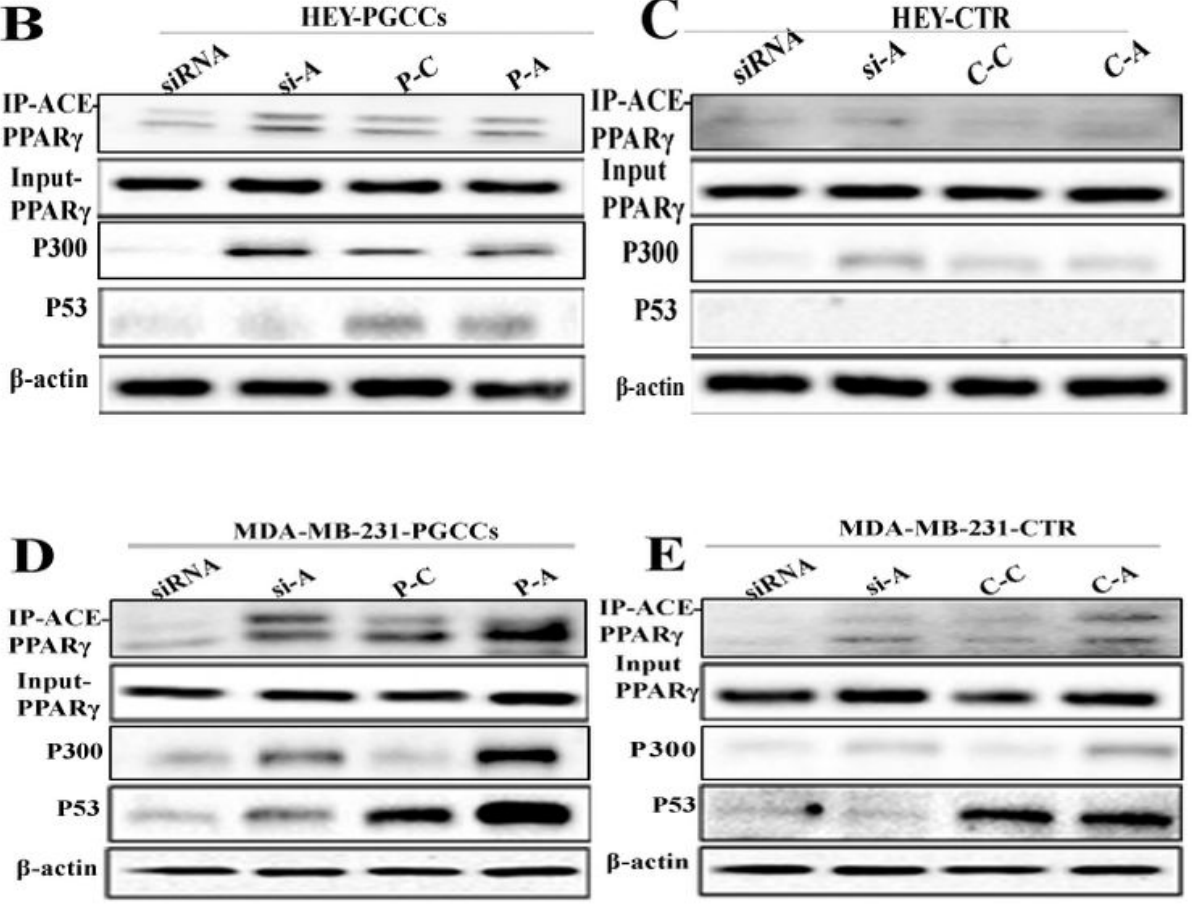

F
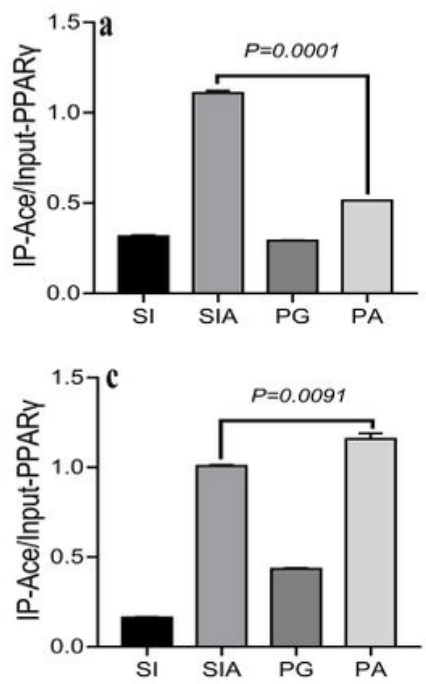
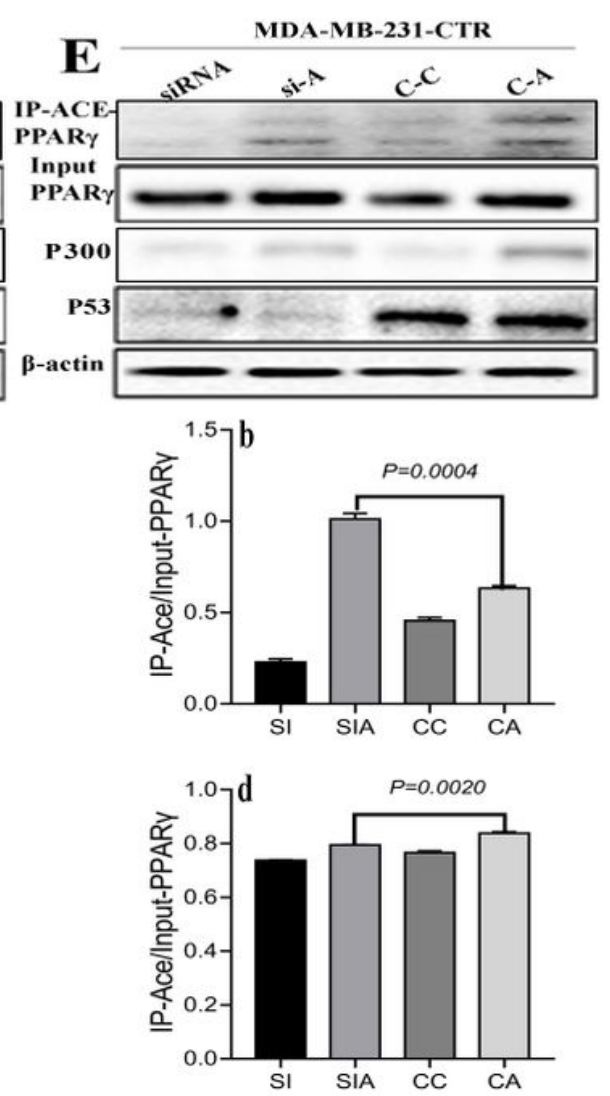

Figure 8

P300-P53 regulate the acetylation of PPARy in the adipogenic differentiation of HEY and MDA-MB-231 (A) Expression of P53 with siRNA P53, siRNA GAPDH, siRNA control, and negative control transfection in (a) HEY polyploid giant cancer cells (PGCCs) with daughter cells, (b) HEY control cells, (c) MDA-MB-231 PGCCs with daughter cells, and (d) MDA-MB-231 control cells. (B)-(E) Expression of ace-PPARy, before and after differentiation, with siRNA P53-985, siRNA control, and negative control transfection in (B) HEY PGCCs with daughter cells, (C) HEY control cells, (D) MDA-MB-231 PGCCs with daughter cells, and (E) MDA-MB-231 control cells. (F) Histograms showing the quantitative results of ace-PPARY expression differences in HEY and MDA-MB-231 control and PGCCs with daughter cells, before and after differentiation, with siRNA P53-985, siRNA control, and negative control transfection. (a) HEY PGCCs with daughter cells. (b) HEY control cells. (c) MDA-MB-231 PGCCs with daughter cells. (d) MDA-MB-231 
control cells. C-C: control cells; C-A: control cells with adipogenic differentiation treatment; P-C: PGCCs with daughter cells; P-A: PGCCs with daughter cells with adipogenic differentiation treatment; si-A: cells with adipogenic differentiation after siRNA P53-985 transfection; si339: siRNA P53-339; si886: siRNA P53-886; si985: siRNA P53-985; siRNA: siRNA P53-985.

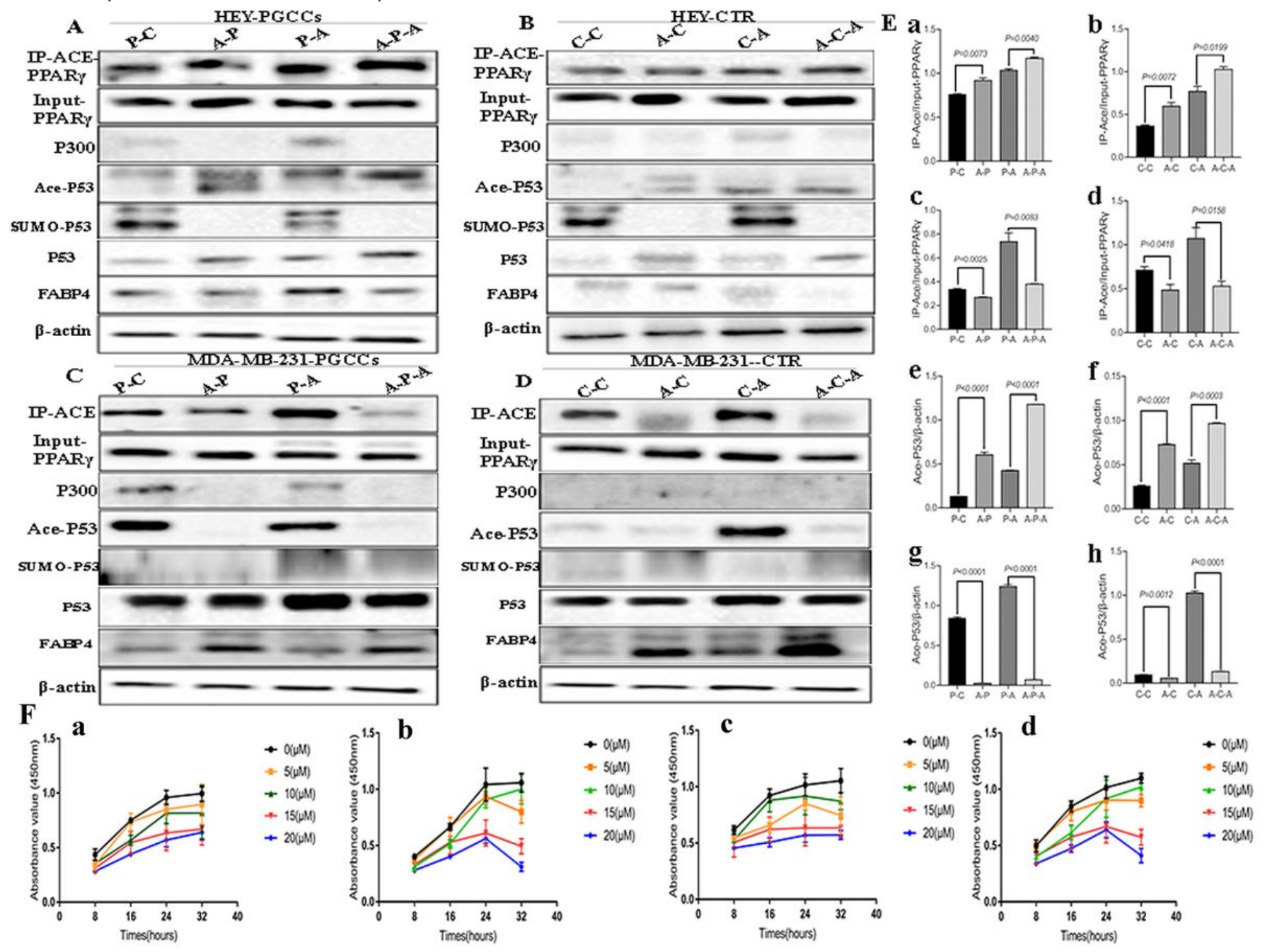

Figure 9

P300-P53 regulate the acetylation of PPARy in adipogenic differentiation of HEY and MDA-MB-231 (A)(D) Effect of A485 treatment on the expression of acetylated PPARy, P300, aceP53, and SUMO-P53 in (A) HEY polyploid giant cancer cells (PGCCs) with daughter cells, (B) HEY control cells, (C) MDA-MB-231 PGCCs with daughter cells, and (D) MDA-MB-231 control cells, before and after differentiation. (E) Histograms showing quantitative results of differences in ace-PPARY and ace-P53 expression in HEY and MDA-MB-231 control and PGCCs with A485 before and after differentiation. (a) ace-PPARy expression in HEY PGCCs with daughter cells. (b) ace-PPARy expression in HEY control cells. (c) ace-PPARy expression in MDA-MB-231 PGCCs with daughter cells. (d) ace-PPARy expression in MDA-MB-231 control cells. (e) ace-P53 expression in HEY PGCCs with daughter cells. (f) ace-P53 expression in HEY control cells. (g) ace-P53 expression in MDA-MB-231 PGCCs with daughter cells. (h) ace-P53 expression in MDA-MB-231 
cells. (F) Cell-counting kit-8 analysis of the effect of A485 on the viability of (a) HEY PGCCs with daughter cells, (b) HEY control cells, (c) MDA-MB-231 PGCCs with daughter cells, and (d) MDA-MB-231 control cells. P-C: PGCCs with daughter cells; P-A: PGCCs with daughter cells with adipogenic differentiation treatment; A-P: PGCCs with daughter cells after A485 treatment; A-P-A: PGCCs with daughter cells with adipogenic differentiation treatment after A485 treatment; C-C: control cells; C-A: control cells with adipogenic differentiation treatment; $\mathrm{A}-\mathrm{C}$ : control cells after $\mathrm{A} 485$ treatment; $\mathrm{A}-\mathrm{C}-\mathrm{A}$ : control cells with adipogenic differentiation treatment after $\mathrm{A} 485$ treatment.
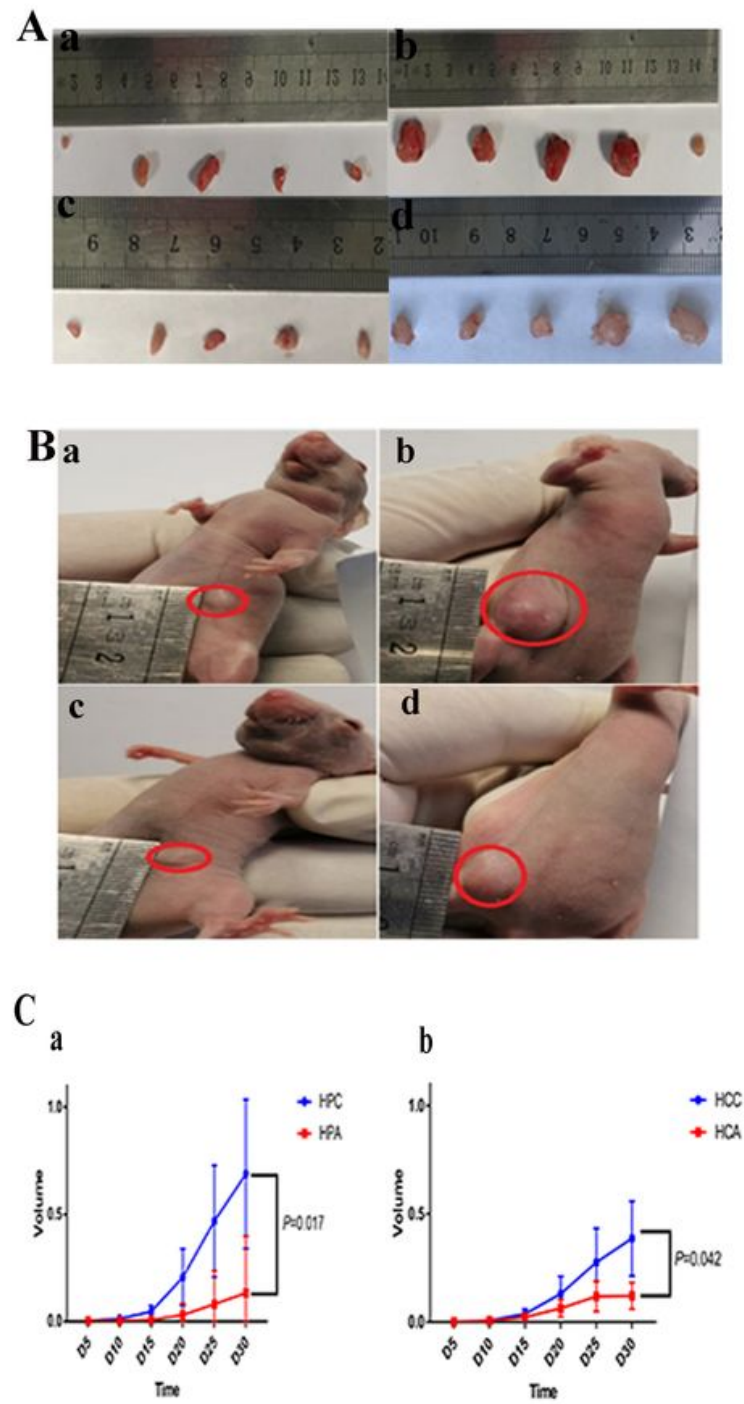
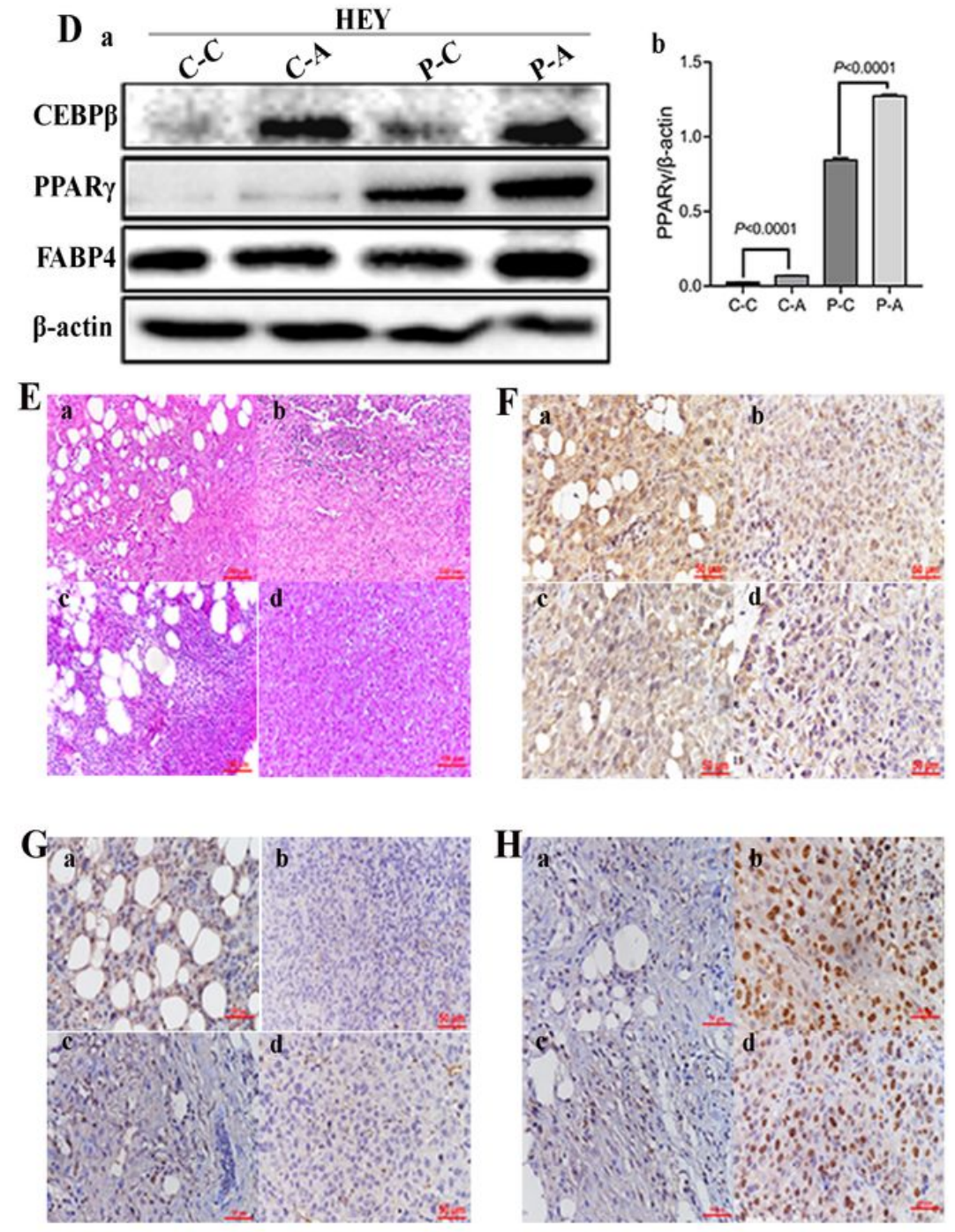

\section{Figure 10}

Ovarian cancer xenograft mice models (A) Tumor volumes of xenograft model on nude mice in HEY cell groups. (B) Tumor morphology of xenograft model on nude mice in HEY cell groups. (C) Tumor growth curves before and after differentiation in (a) HEY polyploid giant cancer cells (PGCCs) with daughter cells and (b) HEY control cells. (D) Total expression of CEBPß, PPARY, and FABP4 in xenograft tumor tissues. (a) Western blot. (b) Statistical graph. (E) Hematoxylin \& eosin staining of the xenograft tumor on nude mice in HEY cells before and after differentiation. $(F)-(H)$ Immunohistochemical staining of $(F)$ Vimentin, (G) Ki-67, and (H) FABP4 in HEY cells before and after differentiation. (a) HEY PGCCs with daughter cells 
after differentiation. (b) HEY PGCCs with daughter cells before differentiation. (c) HEY control cells after differentiation. (d) HEY control cells before differentiation. C-C: control cells; C-A: control cells with adipogenic differentiation treatment; P-C: PGCCs with daughter cells; P-A: PGCCs with daughter cells with adipogenic differentiation treatment.
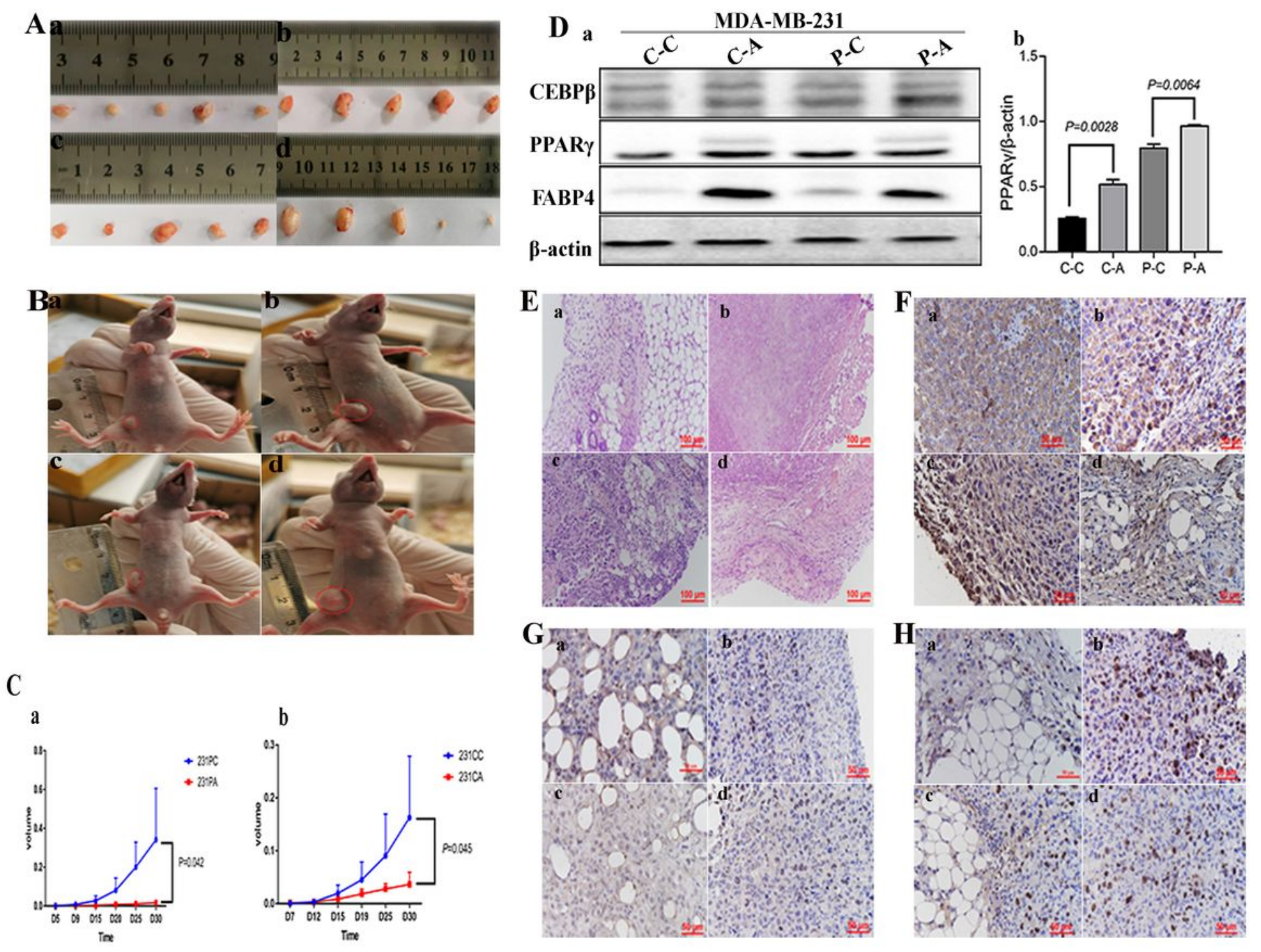

\section{Figure 11}

Breast cancer xenograft mice models (A) Tumor volumes of xenograft model on nude mice in MDA-MB231 cell groups. (B) Tumor morphology of xenograft model on nude mice in MDA-MB-231 cell groups. (C) Tumor growth curves before and after differentiation in (a) MDA-MB-231 polyploid giant cancer cells (PGCCs) with daughter cells and (b) MDA-MB-231 control cells. (D) Total expression of CEBP $\beta$, PPARY, and FABP4 in xenograft tumor tissues. (a) Western blot. (b) Statistical graph. (E) Hematoxylin \& eosin staining of the xenograft tumor on nude mice in MDA-MB-231 cells before and after differentiation. (F)(H) IHC staining of (F) Vimentin, (G) Ki-67, and (H) FABP4 in MDA-MB-231 cells before and after differentiation. (a) MDA-MB-231 PGCCs with daughter cells after differentiation. (b) MDA-MB-231 PGCCs with daughter cells before differentiation. (c) MDA-MB-231 control cells after differentiation. (d) MDA-MB231 control cells before differentiation. C-C: control cells; C-A: control cells with adipogenic differentiation 
treatment; P-C: PGCCs with daughter cells; P-A: PGCCs with daughter cells with adipogenic differentiation treatment.

\section{Supplementary Files}

This is a list of supplementary files associated with this preprint. Click to download.

- supplementaryTables.doc

- supplementaryfiguresandfigurelegends.docx 